\title{
Security Design in Production Economy with Flexible Information Acquisition*
}

\author{
Ming Yang \\ Yao Zeng \\ Duke University \\ Harvard University
}

December, 2012

\begin{abstract}
This paper investigates the optimal security design in an economy with production through the lens of information acquisition. It highlights the role of investors as information experts, who are capable to acquire information on the market prospects of entrepreneurs' technologies and then help to stand out good projects by their financing decisions. Thus, real production depends on information production while these two are separated between the entrepreneur and the investor, which constructs a tension. The optimal security helps to reconcile this tension. The model predicts standard debt as the optimal security when information acquisition is not worthwhile, and more interestingly, convertible preferred stock as the optimal security when information acquisition is crucial for production. Both cases are consistent with empirical evidences, and they also deliver new perspectives to revisit the classic pecking order theory and net present value criterion. Key factors that determine the form of the optimal security are highlighted by performing comparative statics of the optimal security. A new approach, flexible information acquisition, enables us to specify securities on continuous states and deliver sharper predictions than previous literature. It also helps to reveal the interplay between the shape of securities and the qualitative nature of information being acquired more explicitly.
\end{abstract}

KEYWORDS: information acquisition, production economy, security design

JEL: D82, D86, G24, G32, L26

*Preliminary and incomplete. Earlier versions of this paper have been circulated under the title, "Venture Finance under Flexible Information Acquisition." For helpful comments we thank John Campbell, Emmanuel Farhi, Simon Gervais, Barney Hartman-Glaser, Ben Hebert, Steven Kaplan, Arvind Krishnamurthy, Josh Lerner, Stephen Morris, Jon Parker, Raghu Rajan, Adriano Rampini, David Robinson, Hyun Shin, Andrei Shleifer, Alp Simsek, S. Viswanathan, and Michael Woodford; and seminar participants at Duke University, Harvard University, MIT, and Peking University. 


\section{Introduction}

Highlighting information acquisition, this paper studies optimal security design in a prototype production economy. The main goal of this paper is to explore why and how various projects are financed by issuing various securities, through uncovering the role of information acquisition involved. In our stylized model, an entrepreneur has exclusive access to a technology for a risky project, but she has no money for the initial investment. Nevertheless, she may attempt to finance the project through contracting with an investor. Importantly, the investor is also an information expert, who can acquire costly information about the project's uncertain future cash flow before making her financing decision. In other words, the investor does not only finance the entrepreneur's project but also helps to screen in good projects through information acquisition. Therefore, the real production and the production of information are separated in the economy, but the former depends on the latter. The optimal security, which is written on the project's future cash flow, is of interest in this context, because it reconciles two important conflicting forces. On the one hand, to compensate the investor more is desirable from the entrepreneur's perspective, because it induces the investor to acquire information more effectively, which benefits the project and thus the social surplus. On the other hand, as the entrepreneur always shares the social surplus with the investor, she also wants to keep her own share as large as possible by compensating the investor less. Importantly, these two conflicting forces reflect the fundamental tension between the separation and dependence of real production and information production, and the optimal security thus reconciles this tension. Especially, the shapes of the optimal securities in different circumstances also speak to the different roles of information acquisition, accordingly.

Our framework accommodates a variety of theoretical contexts of corporate finance as well as real-world scenarios of production and entrepreneurship. On the one hand, most importantly, we highlight the investor as an information expert. In particular, the investor is more capable to acquire information about the uncertain market prospects of the technology, thanks to her industry experience. The investor thus helps to stand out good projects through her financing decision. The acknowledgement of information acquisition in production and entrepreneurship is dated back to Knight (1921) and Schumpeter, Joseph (1942). As surveyed by Da Rin, Hellmann and Puri (2011), although entrepreneurs may have some information advantage on their own technology, modern investors, like venture capitalists, angel investors, and specialized banks, often have more expertise in acquiring information about the uncertain market prospects of new technologies and business models by their industry experience. Investors thus help to screen in good projects by such information expertise. Besides numerous anecdotal evidences (c.f. Kaplan and Lerner (2010) for a review), recent empirical literature (Kerr, Lerner and Schoar, 2011; Chemmanur, Krishnan and Nandy, 2012) have also acknowledged the screening effects of various investors. On 
the other hand, we highlight two aspects of the entrepreneur. First, the entrepreneur has access to the technology but is financially constrained. Second, the entrepreneur's human capital is not transferrable, which means the project can not be initiated by anyone else even if a buyout of the technology is possible. These fit closely with the argument in Rajan (2012) that the differentiation of entrepreneurs is important in the early stage of firms' life cycles. This paper, to the best of our knowledge, is the first to explicitly investigate the interplay between information acquisition and security design in a production economy, and deliver specific predictions that are consistent with empirical evidences regarding the contracts between real-world entrepreneurs and investors Kaplan and Stromberg (2003).

Our predictions shed lights on the relationship between information acquisition and security design in a production economy. Importantly, we can formulate the optimal securities that are employed to finance various projects differing in nature. In terms of the allocation of cash flow rights, the entrepreneur's optimal securities in our model corresponds to the standard debt and the convertible preferred stock. The trade-off between the benefit and cost of information acquisition plays a crucial role here.

When the dependence of real production on information production is weak, namely, the benefit of information acquisition is small, the optimal security is a standard debt that does not induce the investor to acquire information. This case corresponds to the scenarios in which the project's ex-ante market prospect is clear and good enough relative to its initial investment. Thus, the benefit of screening by information acquisition does not justify the information cost. Therefore, it is optimal to deter information acquisition by issuing a standard debt, which is the least information sensitive security as noted by conventional wisdom (Myers and Majluf, 1984; Gorton and Pennacchi, 1990).

In contrast, when the dependence of real production on information production is strong, namely, the benefit of information acquisition is large, the optimal security turns out to be a participating convertible preferred stock that induces information acquisition. In finding this result (as well as standard debt in the previous case), we do not have any restrictions on the space of feasible securities, and the payoff function is defined on continuous states as opposed to finite discrete states as often seen in literature. So the prediction is sharp and robust. This prediction is new to the security design literature, but it is closely in line with empirical facts, both qualitatively and quantitatively. As documented in Kaplan and Stromberg (2003), four fifth of contracts between real-world entrepreneurs and venture capitalists are convertible preferred stocks, and half of them are participating. The multiple of the convertible preferred stock, predicted in our model, is always larger than one, which also matches the empirical documents in Lerner, Leamon and Hardymon (2012). This case corresponds to the scenarios when the project's exante market prospect is not clear enough relative to its initial investment. Information here is 
more valuable as it updates the investor's perceived market prospect of the project, and thus may eventually help to stand out good projects which look mediocre at the first place. Thus, the shape of optimal securities indeed characterizes the detailed information acquired by the investor in financing the project. The conventional wisdom of expected net present value (NPV) criterion is also challenged, as a project with negative expected NPV may also be financed after the investor acquires information. This is indeed consistent with the screening role of investors that they employ their industry experience to screen in risky but potentially outstanding projects. As a result, the entrepreneur is willing to compensate the investor more to encourage such beneficial information acquisition. Especially, the entrepreneur wants to design such a security that pays generously in general, but differently across states, which encourages the investor to acquire more information to distinguish between different states. This also suggests that standard equity is not optimal because it pays too little in bad states, which again fits the reality that standard equity is the least used security in financing new projects (Lerner, Leamon and Hardymon, 2012). In this sense, combining our arguments that debt is optimal when information acquisition is not worthwhile while convertible preferred stock is optimal when information acquisition is crucial, the optimality of debt and convertible preferred stock in different circumstances contributes to the celebrated pecking order theory (Myers and Majluf, 1984) with new intuitions in the presence of production and information acquisition.

The optimal security not only changes with the dependence of real production on information production, namely, the benefit of information acquisition; it also changes as the characteristics of investors vary, mainly in their expertise in acquiring information, modeled as information costs. The latter dimension allows our analysis to cover various types of investors, including venture capitalists, angel investors, specialized banks and other financial institutions. Concretely, we figure out several key factors that determine the form of the optimal security by performing comparative statics of the optimal security. These factors include the scale and risk of the project, as well as the difficulty in evaluating the market prospect of the project, which is measured by the investor's information cost. These comparative statics speak to the fact that different projects are endogenously financed by different securities and potentially different types of investors. Accordingly, the role of information acquisition is different as well.

A comparison between production economy and exchange economy helps to highlight the essence of the relationship between information acquisition and security design. Yang (2012a) considers the role of information acquisition in an exchange economy and focuses on the unique optimality of debt. In that model, a seller has an asset in-place and proposes an asset-backed security to a buyer to raise liquidity. The buyer can acquire information about the fundamental of the asset before her purchase decision, which leads to endogenous adverse selection. The buyer collects the most payoff-relevant information determined by the shape of the security, and thus the 
seller designs the security in order to induce the buyer to acquire information least harmful to the seller's interest. Debt is shown to be uniquely optimal in this case because it is least information sensitive and mitigates adverse selection to the greatest extent. A key feature driving the unique optimality of debt is that the seller's asset is already in-place, which means the aggregate risk is fixed in such an exchange economy. Importantly, in this exchange economy, the social surplus depends negatively on information acquisition. This is because first, information acquisition leads to endogenous adverse selection and thus creates illiquidity, and second, information is costly per se. As a result, to discourage information is always desirable. On the contrary, in this paper, the entrepreneur's project can only be initiated if it is financed by the investor. Therefore, it is a production economy in which the aggregate risk is variable and thus the net social surplus (information cost excluded) depends positively on information acquisition. In this case, adverse selection is no longer the focus. Instead, the entrepreneur wants to design such a security that encourages the investor to acquire information that is favorable to the entrepreneur's interest, as we discussed above. Therefore, debt is no longer optimal when information acquisition is desirable.

A new concept, flexible information acquisition, plays an important role in revealing the relationship between information acquisition and security design. As described above, designing securities interacts with the investor's incentive of allocating attention in different aspects of the underlying cash flow when acquiring information. It thus calls for a sufficiently flexible characterization of information acquisition to capture the potential variety of attention allocation. In acquiring information about the underlying cash flow, for instance, a debt holder would allocate her attention to bad states as only the default risk matters, while an equity holder wants to pay more attention to good states as she benefits more from enjoying the upside payments. For an arbitrary security, the investor's incentive of information acquisition, in the sense of attention allocation, would be determined in such a way accordingly, and this in turn affects the the entrepreneur's incentive to design the security. In characterizing these effects, the traditional approach of exogenous information asymmetry is inadequate. Moreover, classic models of information acquisition also fail to deliver such flexible allocation of attention, since they implicitly impose some rigid information acquisition technologies with restrictions on signals (cf. Veldkamp (2011) for a review). Because of such rigidity, the interplay between information acquisition and security design cannot be fully analyzed. In contrast, our new approach of flexible information acquisition following (Yang, 2012a,b) allows agents to choose not only how much information, namely, the quantitative nature of information to acquire, but also the qualitative nature of their information. Concretely, flexible information acquisition employes rational inattention Sims (2003) as a foundation. But it switches the gear from macroeconomic decision problems to microeconomic strategic interactions as a new target, in which agents can actively 
use their information capacities to choose any information structure (i.e., conditional distribution of signal realization given the fundamental). Such information structure characterizes both quantitative and qualitative nature of information acquired, which is shaped by the underlying securities. This interplay between security design and information acquisition can be captured by neither exogenous information asymmetry nor rigid information acquisition models. It further renders our very specific predictions on the shape of security possible, which cannot be achieved in previous literature.

Relation to the literature. Our model contributes to the literature of venture contracts by highlighting information acquisition as a new channel, which is highly relevant but overlooked in past theoretical research. Although contract and security design is the focus of modern research in innovation and entrepreneurial finance, existing theoretical literature mainly pay attention to the aspects of monitoring and moral hazard (Schmidt, 2003; Casamatta, 2003; Hellmann, Thomas, 2006), refinancing and staging of finance (Bergemann and Hege, 1998; Cornelli and Yosha, 2003; Repullo and Suarez, 2004), as well as allocation of control rights (Berglof, 1994; Hellmann, Thomas, 1998; Kirilenko, 2001; de Bettignies, 2008), leaving the role of screening and information acquisition largely untouched. Also, existing models often fail to deliver consistent theoretical predictions with real-world securities between entrepreneurs and venture investors. For instance, as documented in Da Rin, Hellmann and Puri (2011), the most commonly used double moral hazard models are able to approximately predict the contract of convertible debt between entrepreneurs and venture capitalists, but these models cannot deliver the correct specific allocation of cash flow rights between the two parties.

Moreover, our model delivers clear implications on liquidity provision and the associated specific allocation of cash flow rights in various economies and financial markets. In this model, the aggregate risk is variable since it depends on the financing decision of the project in the production economy, so that the circumstance could also be viewed as a primary financial market. In contrast, the circumstance of Yang (2012a), where the aggregate risk is fixed, could be viewed as an exchange economy or a secondary financial market. Such comparison further helps us understand why different optimal securities arise in different circumstances. Earlier mechanism design literature pertaining to information gathering also highlight such comparison between different economies or financial markets and suggest that the value of information would be different accordingly (Cremer and Khalil, 1992; Cremer, Khalil and Rochet, 1998a,b). But these papers do not focus on the security design problem and cannot make specific predictions on the forms of contracts in different economies or financial markets. Together with Yang (2012a), this paper fills this gap by delivering specific forms of securities for liquidity provision in different circumstances.

This paper is also closely related to a series of theoretical work on information, screening and 
optimal security design. These models predict non-debt-like securities in various circumstances where information asymmetry may be favorable (Nachman and Noe, 1994; Fulghieri and Lukin, 2001; Inderst and Mueller, 2006; Hennessy, 2009; Chakraborty and Yilmaz, 2011; Dow, Goldstein and Guembel, 2011; Fulghieri, Garcia and Hackbarth, 2012). Compared to those papers, most of which focus on ex-ante information asymmetry or rigid information acquisition, our model delivers clearer interaction between security design and the corresponding information asymmetry resulted from information acquisition. This enables us to capture the role of information more explicitly in characterizing the optimal security between entrepreneurs and investors. Also, most models in previous literature can only accommodate discrete states. Thanks to the technique of flexible information acquisition, our framework enables us to model securities on continuous states and thus to characterize the shapes of optimal securities more specifically. Through this line, our model also highlights the standard intuition of information sensitiveness that non-debt-like securities may encourage investors to acquire information and facilitate information aggregation in a more precise manner.

The rest of the paper is organized as follows. Section 2 specifies the environment of the prototype production economy and elaborates the concept of flexible information. Our key results, the optimal securities in equilibrium, are solved and discussed in Section 3. Section 4 performs comparative statics on the optimal securities. In the final section, we conclude and discuss possible directions for further research. If otherwise noted, all proofs are attached in the appendix.

\section{Model}

We present our stylized model of production economy, focusing on the finance of new projects. This model does not aim to capture every aspect of finance and production. Instead, we make assumptions to highlight the analysis of security design and focus on the essence of flexible information acquisition, which will be rigorously characterized in this section. We will discuss these assumptions and their implications in detail.

\subsection{Finance in A Prototype Production Economy}

Consider an economy with two dates, $t=0,1$, and a single consumption good (money). There are two agents in this economy: an entrepreneur and a deep-pocket investor. Both agents are risk neutral. Their utility function is the sum of consumptions over the two dates:

$$
u=c_{0}+c_{1}
$$

where $c_{t}$ denotes agent's consumption at date $t$. We assume that the entrepreneur starts at date 0 with zero initial wealth, while the deep-pocket investor has large endowment at date 0 . In what 
follows we use the subscripts $E$ and $I$ to indicate the entrepreneur and the investor, respectively.

We consider the technology owned by the entrepreneur and the finance of a risky project. To initiate the project at date 0 , the underlying technology requires a capital investment $k>0$. The project cannot be initiated partially. Hence, the entrepreneur has to borrow $k$ from the investor, by selling a security to the investor at date 0 . The security traded constructs the contract between the two agents, so that we take the terms security and contract in what follows to mean the same thing and use them exchangeably. We focus on the cash flow aspect of securities and projects. If initiated, the project generates a non-negative verifiable random cash flow $\theta$ at date 1 .

We specify the processes of security design and information acquisition. The payment of an asset-backed security at date 1 is a mapping $s: \mathbb{R}_{+} \rightarrow \mathbb{R}_{+}$such that $s(\theta) \in[0, \theta]$ for any $\theta$. At date 0 , both agents have a common prior $P$ on the future cash flow $\theta$ of the project, if initiated. The entrepreneur designs the security, and then proposes a take-it-or-leave-it offer to the investor at price $k$ at date 0 . Facing the offer, the investor acquires information about the future cash flow $\theta$ in the manner of rational inattention (Sims, 2003; Yang, 2012a,b), and then decides whether to accept the offer. This characterizes the process of flexible information acquisition, where the information acquired is measured by reduction of entropy. The information cost per unit reduction of entropy is $\mu$. The concept of flexible information acquisition will be further elaborated in the next subsection. The entrepreneur could initiate the project if and only if the investor accepts the offer. This highlights the variable aggregate risk as a key feature in the finance of projects in a production economy.

The implicit assumptions in the settings above are justified to capture the key features in the finance of projects, especially from an information acquisition perspective. First, both agents have a common prior on the uncertain profitability of the project but only the investor is able to acquire further information, which highlights the investor's information advantage in understanding market prospects. This point not only accounts for the empirical evidences that investor screen projects by their information expertise but also stands our framework out from most previous security design literature that feature the entrepreneur's exogenous information advantage. Second, the entrepreneur owns the technology while the investor has money, which reflects the separation of technology and money. In particular, we assume that the entrepreneur has no money at all. This implies that the entrepreneur always prefers the project to be initiated, which is consistent with real practices. This is also consistent with earlier evidences that entrepreneurs are often financially constrained (Evans and Jovanovic, 1989; Holtz-Eakin, Joulfaian and Rosen, 1994). Even in mature firms, managers seek for outside finance if the internal capital market does not function well for new risky projects (Stein, 1997; Scharfstein and Stein, 2000). Also, we assume that the entrepreneur's human capital is not transferrable, which means the project can not be initiated by anyone else even if a buyout of the technology is possible. Together with the differentiation 
argument in Rajan (2012), this assumption also broadly corresponds to the earlier incomplete contract literature which suggest the ownership go to the entrepreneur when innovative firms are young (Aghion and Tirole, 1994). Based on these settings, the separation of technology and money further enables the separation of real production and information production, which is one of the key forces in our framework.

It is also worth highlighting what aspects of the finance in a production economy are abstracted away from the model, and to what extent these aspects affect our work. First, to focus on information acquisition and screening, we put the potential of moral hazard aside. To ignore moral hazard is a general practice in the security design literature, especially when information asymmetry is highlighted (see DeMarzo and Duffie, 1999; DeMarzo, 2005). Second, investors are unlikely to be risk neutral in reality. Nevertheless, the assumption of risk neutrality enables us to first focus on the role of information acquisition as opposed to risk sharing, which is of less interest for our purpose. Actually, our results would be only strengthened if we take investors' risk aversion into account, which will be illustrated later. So we follow the risk neutral assumption to streamline our presentation and focus on the essence. Third, an interim cash flow is unlikely to play a key role in the real-world finance setting. For example, most of the literature suggests that venture capitalist-backed firms lose money until well after going public and the exiting of the venture capitalists (Kaplan and Lerner, 2010; Da Rin, Hellmann and Puri, 2011). We therefore interpret the cash flow $\theta$ in our model as an ex-post one, which already takes the consequence of investors' exiting into account. In other words, the exiting nature of investors is already incorporated in the distribution of the future cash flow. This allows us to model a variety of investors not limited to venture capitalists, as well as to focus on the aspect of information acquisition. Fourth, we do not explicitly consider discounting. Our results and underlying mechanisms do not rely on the discount between the two periods. Last, the bargaining process is abstracted as a take-itor-leave-it offer from its reality. This also implies that the allocation of control rights is not our focus.

\subsection{Flexible Information Acquisition}

We follow Yang (2012a) to characterize the way through which the investor acquires information. In Yang (2012a), the author elaborates a general environment where an agent acquires information and thus makes a binary choice. The environment constructs the workplace of flexible information acquisition. ${ }^{1}$ This environment and its corresponding implications also apply to our framework in this paper.

Consider an agent who chooses a binary action $a \in\{0,1\}$ and receives a payoff $u(a, \theta)$, where

\footnotetext{
${ }^{1}$ For more detailed justification of this environment, see Woodford (2008) and Yang (2012a,b).
} 
$\theta \in \Theta=\mathbb{R}_{+}$is the fundamental, distributed according to a continuous probability measure $P$ over $\Theta$. Before making the decision, the agent has access to a set of binary-signal information structures. $^{2}$ In particular, she observes binary signals $x \in\{0,1\}$ parameterized by a measurable function $m: \Theta \rightarrow[0,1]$, where $m(\theta)$ is the probability of observing signal 1 if the true state is $\theta$. When observing signal 1 , the agent's optimal action is 1 . The conditional probability function $m(\theta)$ describes the agent's decision rule of information acquisition. By choosing different functional forms of $m(\theta)$, the agent can make her signal covary with fundamental in any arbitrary way. Intuitively, for instance, if the agent's payoff is sensitive to fluctuations of the state within some range $A \subset \Theta$, she would pay more attention to this range by specifying $m(\theta)$ to be highly sensitive to $\theta \in A$. This example also illustrates the concept of flexible information acquisition. As opposed to classic information acquisition technologies that often involve restrictions on the signals to be acquired, flexible information acquisition allows agents to choose signals drawn from any conditional distribution of the fundamental. The functional form of $m(\theta)$, intuitively, its shape, determines the quantity and quality of information acquired.

We then characterize the quantitative and qualitative nature of information. As in Yang (2011a), information conveyed by an information structure $m(\cdot)$ is defined as the expected reduction of uncertainty through observing the signal generated by $m(\cdot)$, where the uncertainty associated with a distribution is measured by Shannon (1948)'s entropy. Specifically, to formulate the process of flexible information acquisition and the underlying transition from prior to posterior, we employ the concept of mutual information, which is defined as the difference between agents' prior entropy and expected posterior entropy:

$$
\begin{aligned}
I(m) & =H(\text { prior })-H(\text { posterior }) \\
& =-g\left(\mathbb{E}_{\Theta}[m(\theta)]\right)-\left(-\mathbb{E}_{\Theta}[g(m(\theta))]\right) \\
& =\mathbb{E}_{\Theta}[g(m(\theta)])-g\left(\mathbb{E}_{\Theta}[m(\theta)]\right),
\end{aligned}
$$

where

$$
g(x)=x \cdot \ln x+(1-x) \cdot \ln (1-x),
$$

and the expectation operator $\mathbb{E}_{\Theta}(\cdot)$ is with respect to $\theta$ under the probability measure $P$. In what follows we omit the subscript $\Theta$ for simplicity.

We specify the cost of information. Denote $M=\{m \in L(\Theta, P): \theta \in \Theta, m(\theta) \in[0,1]\}$ as the set of binary-signal information structures. Let $c: M \rightarrow \mathbb{R}_{+}$be the cost of information. As in Yang (2012a), we assume that the cost is proportional to the associated mutual information:

$$
c(m)=\mu \cdot I(m),
$$

\footnotetext{
${ }^{2}$ In general, an agent can get access to any information structure. But it could be shown that the agent always prefers binary-signal information structures in binary decision problems. See Woodford (2009) and Yang (2012b) for more discussions.
} 
where $\mu>0$ is the marginal cost of information acquisition. This concludes the general environment of binary decision problem with flexible information acquisition.

Built upon the concept of flexible information acquisition, the agent's problem is to choose a functional form of $m(\theta)$ to maximize her expected payoff minus the information cost. We characterize the optimal decision rule $m(\theta)$ in the following proposition. We denote $\Delta u(\theta)=$ $u(1, \theta)-u(0, \theta)$, which is the the payoff gain of taking action 1 over action 0 . We also assume that $\operatorname{Pr}[\Delta u(\theta) \neq 0]>0$ to exclude the trivial case where the agent is always indifferent between the two actions. The proof is in Yang (2012a).

Proposition 1. Yang (2012A) Given $u, \Theta, P$, and $\mu$, let $m(\theta) \in M$ be an optimal decision rule and

$$
\bar{p}=\mathbb{E}[m(\theta)]
$$

be the corresponding unconditional probability of taking action 1. Then,

i) the optimal decision rule is unique;

ii) there are three cases for the optimal decision rule:

a) $\bar{p}=1$, i.e., $\operatorname{Pr}(m(\theta)=1)=1$ if and only if

$$
\mathbb{E}\left[\exp \left(-\mu^{-1} \cdot \Delta u(\theta)\right)\right] \leqslant 1
$$

b) $\bar{p}=0$, i.e., $\operatorname{Pr}(m(\theta)=0)=1$ if and only if

$$
\mathbb{E}\left[\exp \left(\mu^{-1} \cdot \Delta u(\theta)\right)\right] \leqslant 1 ;
$$

c) $0<\bar{p}<1$ if and only if

$$
\mathbb{E}\left[\exp \left(\mu^{-1} \cdot \Delta u(\theta)\right)\right]>1 \text { and } \mathbb{E}\left[\exp \left(-\mu^{-1} \cdot \Delta u(\theta)\right)\right]>1 ;
$$

in this case, the optimal decision rule $m(\theta)$ is determined by the equation

$$
\Delta u(\theta)=\mu \cdot\left(g^{\prime}(m(\theta))-g^{\prime}(\bar{p})\right)
$$

for all $\theta \in \Theta$, where

$$
g^{\prime}(x)=\ln \left(\frac{x}{1-x}\right) .
$$

Proposition 1 fully characterizes the agent's possible optimal decisions of information acquisition. Case a) and case b) correspond to the scenario where the prior is extreme in the sense that there exists an ex-ante optimal action 1 or 0 . These two cases do not involve information acquisition, and thus they also correspond to the scenario where the cost of information acquisition is sufficiently high. In contrast, case c), the more interesting one, involves information acquisition. Especially, the optimal decision rule $m(\theta)$ is not constant in this case, and neither action 1 nor 
action 0 is ex-ante optimal. Intuitively, this case corresponds to the scenario where the prior is not extreme, or the cost of information acquisition is sufficiently low. In case c) where information acquisition is involved in the optimal decision rule, the agent equates the marginal benefit of information to the marginal cost of information. By doing so, the agent chooses the shape of her optimal decision rule $m(\theta)$ according to the shape of payoff gain $\Delta u(\theta)$ and her prior $P$, which process is consistent with the essence of flexible information acquisition. ${ }^{3}$

\section{Security Design}

We consider the security design problem between the entrepreneur and the investor. We denote the entrepreneur's optimal security by $s^{*}(\theta)$. The strategic circumstance between the entrepreneur and the investor is a dynamic Bayesian game with sequential moves. Concretely, the entrepreneur first designs the security, and then the investor acquires information according to the security and decides whether to accept it. In Proposition 1, we have characterized the general optimal decision rule for the agent who acquires information. Hence, we apply the results in Proposition 1 to the investor's decision problem, given the entrepreneur's proposal, and then solve for the entrepreneur's optimal security by backward induction. To distinguish from the general decision problem discussed above, we denote the investor's optimal decision rule of information acquisition as $m_{s}(\theta)$, given the security $s(\theta)$. The investor's optimal decision rule of information acquisition given the entrepreneur's optimal security $s^{*}(\theta)$ will be denoted by $m_{s}^{*}(\theta)$.

We formally define the equilibrium of this model as follows.

Definition 1. The sequential equilibrium is defined as a collection of the entrepreneur's optimal security $s^{*}(\theta)$ and the investor's optimal decision rule of information acquisition $m_{s}^{*}(\theta)$ based on which:

i). Given $u, \Theta, P, k$ and $\mu, s^{*}(\theta)$ and $m_{s}^{*}(\theta)$ maximize the expected payoffs of the entrepreneur and the investor, respectively.

ii). Both agents use the Bayes' rule to update their beliefs about the fundamental $\theta$, and follow sequential rationality.

According to Proposition 1, there are three cases pertaining to the investor's behavior, given the entrepreneur's optimal security. First, the investor may optimally choose to not acquire any information and accept the entrepreneur's optimal security directly. This implies the project would be financed for sure. Second, the investor may optimally acquire some information, induced by the entrepreneur's optimal security, and then accept the entrepreneur's optimal security with positive (but less than one) probability . In this case, the project would be financed with positive

\footnotetext{
${ }^{3}$ See Woodford (2008), Yang (2012a,b) for more examples on this decision problem.
} 
(but less than one) probability in an ex-ante sense. Third, the investor may directly reject the entrepreneur's optimal security without any information acquisition, which implies the project would not be financed. All the three cases could be accommodated by the equilibrium definition, and they may correspond to three types of equilibrium. This last case, however, corresponds to the outside option of the entrepreneur, who can always propose nothing to the investor and end up skipping the project. Thus, it is less interesting to characterize the last case explicitly, and we will focus on the first two types of equilibrium.

The following proposition helps to distinguish the first two cases from the last case. If the condition given is satisfied, the optimal security in equilibrium would be a non-trivial one and it would be accepted with positive probability.

Proposition 2. The project is financed and thus initiated with positive probability in equilibrium if and only if

$$
\mathbb{E}\left[\exp \left(\mu^{-1}(\theta-k)\right)\right]>1
$$

Proposition 2 is intuitive. It implies that the security would more likely be accepted, if the prior of the project's market prospect is better, if the initial investment $k$ is smaller, or if the investor's information cost $\mu$ is lower. When condition (3.1) is violated, the investor would reject the security, whatever it is.

The violation of condition (3.1) corresponds to some real-world cases in which a project can never be financed. This is either because the prior of the project's market prospect is too pessimistic, or because the initial investment is too high, or because the nature of the underlying technology is too obscure so that it is too difficult for any investor to access its viability. The last case may correspond to the scenario that, when a technology was first introduced, as the nature of the technology is too advanced to understand at that time, it could not get financed in a long period, but turned out to be a success and eventually valued by the public after a long time of struggle.

It is also interesting to note that the statement of Proposition 2 is different from the standard expected NPV criterion, which suggests that a project should be initiated when $\mathbb{E}[\theta]-k>0$. In particular, according to condition (3.1), some projects with negative expected NPV may be initiated with positive probability. Thus, in our context of finance with information acquisition, it is not helpful anymore to follow the standard present value as an efficiency criterion. As the investor is able to acquire information about the fundamental $\theta$ and update her belief accordingly, the standard expected NPV based on the prior is not valid. In this sense, Proposition 2 revises the standard expected NPV criterion and provides a new investment criterion which is robust to the potential of information acquisition. This point is in fact central to our main idea that real production may depend on information production in a production economy. This also calls for 
a new efficiency criterion to help us perform the welfare analysis, which will be elaborated later.

In what follows, we assume condition (3.1) is satisfied, and characterize the entrepreneur's optimal security, focusing on the first two types of equilibrium. Specifically, we pay attention to the shape of the optimal securities and its interplay with information acquisition. As we will see below, the entrepreneur's optimal securities in these two cases are different. This difference also implies different relationships between the shapes of securities and the roles of information. We will finally separate the first two types of equilibrium according to some exogenous parameters of the production economy. This allows us to reveal the relationship between the optimal security and the dependence of real production on information production in a clearer manner.

\subsection{Optimal Security without Inducing Information Acquisition}

In this subsection, we consider the case in which the entrepreneur's optimal security is directly accepted by the investor without any information acquisition. In other words, it is optimal for the entrepreneur to design such a security that does not induce the investor to acquire information. Concretely, this means $\operatorname{Pr}\left[m_{s}(\theta)=1\right]=1$. We first consider the investor's problem of information acquisition, given the entrepreneur's security. Then we follow by characterizing the entrepreneur's optimal security.

Given a security $s(\theta)$, the investor's payoff gain by accepting the security over rejecting it is

$$
\Delta u_{I}(\theta)=u_{I}(1, \theta)-u_{I}(0, \theta)=s(\theta)-k .
$$

According to Proposition 1 and conditions (2.1) and (3.2), any security $s(\theta)$ that is accepted by the investor without information acquisition must satisfy

$$
\mathbb{E}\left[\exp \left(-\mu^{-1} \cdot(s(\theta)-k)\right)\right] \leqslant 1 .
$$

In particular, if the left hand side of the inequality (3.3) is strictly less than one, the entrepreneur could always lower $s(\theta)$ to some extent to increase her expected payoff gain, without changing the investor's incentive. Hence, this condition (3.3) always holds as an equality in equilibrium.

Therefore, the entrepreneur's problem is to choose a security $s(\theta)$ to maximize her expected payoff

$$
u_{E}(s(\theta))=\mathbb{E}[\theta-s(\theta)]
$$

subject to the investor's information acquisition constraint

$$
\mathbb{E}\left[\exp \left(-\mu^{-1} \cdot(s(\theta)-k)\right)\right]=1,
$$

the entrepreneur's individual rationality constraint

$$
\mathbb{E}[\theta-s(\theta)] \geqslant 0,
$$


and the feasibility condition $0 \leqslant s(\theta) \leqslant \theta$.

It is interesting to observe that the entrepreneur's individual rationality constraint is automatically satisfied, given the feasibility constraints. This comes from the fact that the entrepreneur is assumed to have no money at all to start. This fact also implies that the entrepreneur always prefers the project to be initiated, which is consistent with the real-world practices. Note that, it is not correct to interpret this in a way that the entrepreneur would like to contract with any individual investor, whatever the security is. This is because we do not explicitly model the competition between different investors, so that the investor in our model indeed represents a collection of all investors in the market.

As we would see, the entrepreneur's optimal security in this case follows a standard debt. We analytically characterize this optimal security by the following proposition, along with its graphical illustration.

Proposition 3. If the entrepreneur's optimal security $s^{*}(\theta)$ induces the investor to accept the security without acquiring information in equilibrium, then it takes the form of a standard debt:

$$
s^{*}(\theta)=\min \left(\theta, D^{*}\right)
$$

where the face value $D^{*}$ is determined by

$$
D^{*}=k-\mu \cdot \ln \left(\lambda^{-1} \cdot \mu\right),
$$

in which $\lambda$ is a positive constant determined in equilibrium.

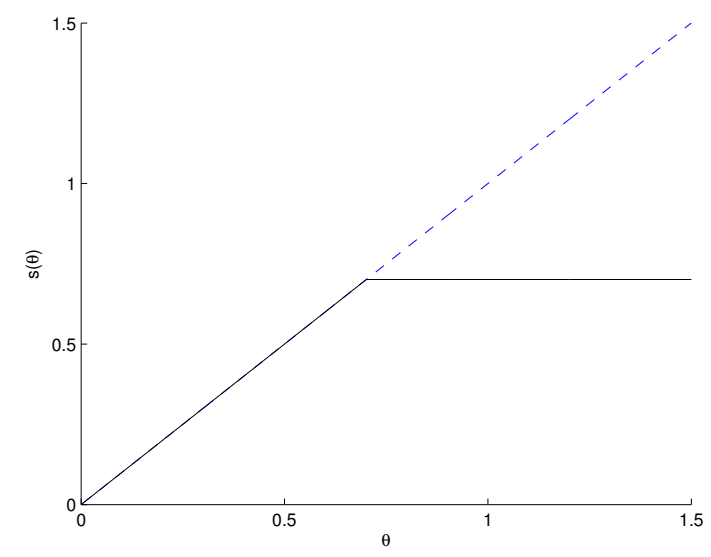

Figure 1: The Unique Optimal Contract without Information Acquisition

It is intuitive to have the standard debt as the optimal security when it does not induces information acquisition. In the case without inducing information acquisition, the optimal security indeed makes the investor break even between acquiring and not acquiring information. Hence, thanks to the definition of flexible information acquisition, any mean-preserving spread of the 
optimal security, which gives the entrepreneur the same expected payoff, would induce the investor to acquire information. Since it is optimal for the entrepreneur to design a less information sensitive security to deter information acquisition in this case, the debt is the least information sensitive one to provide the desired expected payoff to the seller. More specifically, it is the flat part of the debt that mitigates the investor's incentive to acquire information to the extent at which the buyer just wants to give up acquiring information, while delivers the highest possible expected payoff to the entrepreneur. As a result, the debt is the entrepreneur's uniquely optimal choice in this case.

The standard debt, as the optimal security, accounts for to the real-world scenarios in which some projects are financed by short-term fixed-income financial instruments. We will discuss this point in more details below.

\subsection{Optimal Contract Inducing Information Acquisition}

In this subsection, we characterize the entrepreneur's optimal security if it induces the investor to acquire information and accept the security with positive probability (but less than one). In other words, it is optimal for the entrepreneur to design such a security that induces the investor to acquire information. Concretely, this means $\operatorname{Pr}\left[m_{s}(\theta)=1\right] \in(0,1)$.

Again, according to Proposition 1 and conditions (2.2) and (3.2), any security $s(\theta)$ that induces the investor to acquire information must satisfy

$$
\mathbb{E}\left[\exp \left(\mu^{-1}(s(\theta)-k)\right)\right]>1
$$

and

$$
\mathbb{E}\left[\exp \left(-\mu^{-1}(s(\theta)-k)\right)\right]>1
$$

As discussed above, when conditions (3.4) and (3.5) are satisfied, neither accepting nor rejecting the security is ex-ante optimal for the investor. As a result, the investor finds it optimal to first acquire some information and then make the decision according to her posterior. In other words, in this case, the security proposed by the entrepreneur will induce information acquisition by the investor.

Given such a security $s(\theta)$, Proposition 1 and condition (2.3) also prescribe that the investor's optimal decision rule of information acquisition $m_{s}(\theta)$ is uniquely characterized by

$$
s(\theta)-k=\mu \cdot\left(g^{\prime}\left(m_{s}(\theta)\right)-g^{\prime}\left(\bar{p}_{s}\right)\right)
$$

where

$$
\bar{p}_{s}=\mathbb{E}\left[m_{s}(\theta)\right]
$$


is the investor's unconditional probability of accepting the security. In what follows, we also denote this unconditional probability induced by the entrepreneur's optimal security by $\bar{p}_{s}^{*}$. Condition (3.6) concludes the investor's decision problem, given the security $s(\theta)$ proposed by the entrepreneur.

We derive the entrepreneur's optimal security by backward induction. Taking into account of investor's response $m_{s}$, the entrepreneur chooses a security $s(\theta)$ to maximize her expected payoff

$$
u_{E}(s(\theta))=\mathbb{E}\left[m_{s}(\theta) \cdot(\theta-s(\theta))\right]
$$

subject to (3.4), (3.5), ${ }^{4}(3.6)$, the entrepreneur's individual rationality constraint

$$
\mathbb{E}\left[m_{s}(\theta) \cdot(\theta-s(\theta))\right] \geqslant 0,
$$

and the feasibility condition $0 \leqslant s(\theta) \leqslant \theta$.

In characterizing the entrepreneur's optimal security $s^{*}(\theta)$ when it induces information acquisition, we proceed by two steps. First, to streamline the presentation and fix the idea, we solve for an "unconstrained" optimal security in this case without the feasibility condition $0 \leqslant s(\theta) \leqslant \theta$. We denote the solution by $\widehat{s}(\theta)$. We also denote the corresponding information acquisition rule by $\widehat{m}_{s}(\theta) .{ }^{5}$ We try to highlight that the feasibility condition is a mechanical restriction on the potential securities. Importantly, it is not directly relevant to the entrepreneur's motives in designing the securities, which are aiming to induce the investor to acquire information that is most favorable to the entrepreneur. Hence, the unconstrained optimal security $\widehat{s}(\theta)$ helps to reveal the relationship between security design and information acquisition in a clearer manner. After that, we resume the feasibility condition and characterize the exact optimal security $s^{*}(\theta)$. This two-step approach streamlines our presentation and makes the intuition clearer.

For the unconstrained optimal security $\widehat{s}(\theta)$ in the case with information acquisition, we have the following lemma.

LEMMA 1. In an equilibrium with information acquisition, the unconstrained optimal security $\widehat{s}(\theta)$ and its corresponding information acquisition rule $\widehat{m}_{s}(\theta)$ are determined by

$$
\widehat{s}(\theta)-k=\mu \cdot\left(g^{\prime}\left(\widehat{m}_{s}(\theta)\right)-g^{\prime}\left(\bar{p}_{s}^{*}\right)\right)
$$

where

$$
\bar{p}_{s}^{*}=\mathbb{E}\left[m_{s}^{*}(\theta)\right],
$$

\footnotetext{
${ }^{4}$ It is worth noting that, according to Proposition 1, both conditions (3.4) and (3.5) should not be binding for the optimal security; otherwise the investor would not acquire information. See Yang (2012a) for more details.

${ }^{5}$ Note that, $\widehat{m}_{s}(\theta)$ is not exactly the solution to the entrepreneur's problem without the feasibility condition, but is a translation of that solution. This will be seen clearer in the statement of Lemma 1.
} 
and

$$
\left(1-\widehat{m}_{s}(\theta)\right) \cdot\left(\theta-\widehat{s}(\theta)+w^{*}\right)=\mu
$$

where

$$
w^{*}=\mathbb{E}\left[\left(\theta-s^{*}(\theta)\right) \frac{g^{\prime \prime}\left(\bar{p}_{s}^{*}\right)}{g^{\prime \prime}\left(m_{s}^{*}(\theta)\right)}\right]\left(1-\mathbb{E}\left[\frac{g^{\prime \prime}\left(\bar{p}_{s}^{*}\right)}{g^{\prime \prime}\left(m_{s}^{*}(\theta)\right)}\right]\right)^{-1},
$$

in which $\bar{p}_{s}^{*}$ and $w^{*}$ are two constants that do not depend on $\theta$.

Lemma 1 exhibits the relationship between the unconstrained optimal security and the corresponding decision rule for information acquisition. Recall Proposition 1, condition (3.8) specifies how the investor responses to the unconstrained optimal security $\widehat{s}(\theta)$ by adjusting her decision rule of information acquisition $\widehat{m}_{s}(\theta)$. On the other hand, condition (3.9) is derived from the entrepreneur's optimization problem. It describes the entrepreneur's optimal choices of cash flows across states, which is summarized by the unconstrained optimal security, given the investor's decision rule of information acquisition. In equilibrium, $\widehat{s}(\theta)$ and $\widehat{m}_{s}(\theta)$ are jointly determined. This again highlights the close relationship between security design and information acquisition in our context.

Although it is mathematically difficult to solve the system of differential equations (3.8) and (3.9), we are able to deliver some important analytical characteristics of the unconstrained optimal security $\widehat{s}(\theta)$ and the corresponding information acquisition rule $\widehat{m}_{s}(\theta)$. In particular, we are confident enough to speak to the shape of the unconstrained optimal security $\widehat{s}(\theta)$ as well as the actual optimal security $s^{*}(\theta)$ by these analytical properties. The following lemma gives the key results.

LEMMA 2. In an equilibrium with information acquisition, the unconstrained optimal security $\widehat{s}(\theta)$ and the corresponding information acquisition rule $\widehat{m}_{s}(\theta)$ satisfy

$$
\frac{\partial \widehat{s}(\theta)}{\partial \theta}=1-\widehat{m}_{s}(\theta) \in(0,1)
$$

and

$$
\frac{\partial \widehat{m}_{s}(\theta)}{\partial \theta}=\mu^{-1} \cdot \widehat{m}_{s}(\theta) \cdot\left(1-\widehat{m}_{s}(\theta)\right)^{2}
$$

We have several interesting observations from Lemma 2. First, condition (3.10) implies that the unconstrained optimal security $\widehat{s}(\theta)$ is strictly increasing. This is because, by definition, we have $0<\widehat{m}_{s}(\theta)<1$, and thus the right hand side of (3.10) is positive. Second, the unconstrained optimal security $\widehat{s}(\theta)$ is strictly concave. This is because conditions (3.10) and (3.11) imply

$$
\frac{\partial^{2} \widehat{s}(\theta)}{\partial \theta^{2}}=-\mu^{-1} \cdot \widehat{m}_{s}(\theta) \cdot\left(1-\widehat{m}_{s}(\theta)\right)^{2},
$$

the right hand side of which is negative. Therefore, the unconstrained optimal security $\widehat{s}(\theta)$ is an increasing concave function of $\theta$. As opposed to the classic literature in security design, which 
often restrict the attention to non-decreasing securities (Innes, 1990; Nachman and Noe, 1994; DeMarzo and Duffie, 1999; DeMarzo, 2005), it is intuitive to have the increasing unconstrained optimal security as a result of our model. In our context, the investor provides two different types of services to the entrepreneur. The first is the investment required to initiate the project, and the second is the information about the project's market prospect. In particular, these two services work in a way that they affect the probability of acceptance, at which the project takes place. As a result, it is natural for the entrepreneur to compensate the investor more in an event of higher profit, in exchange of these two types of services that make the project possible.

More specifically, Lemma 2, especially the increasing and concave nature of the unconstrained optimal security, reveals the relationship between the shape of the security and the information acquired in a clearer way. Recall that the ratio $\left|\partial \widehat{m}_{s}(\theta) / \partial \theta\right|$ represents the attention placed at state $\theta$ by the investor. When the slope of the security changes more drastically around a state, which implies the change of payoff is more significant, the investor wants to acquire more information around that state. Furthermore, the security is designed by the entrepreneur to take advantage of the investor's information expertise. Hence, the monotonicity and concaveness of the unconstrained optimal security actually reflect the entrepreneur's payoff sensitiveness across states. On the one hand, the unconstrained optimal security is strictly increasing, which always encourages the investor to acquire some information around all states. The reason is straightforward. As the entrepreneur cannot initiate the project by herself, she would like to encourage the investor to acquire information at all states in order to increase the probability of acceptance, at which the project would be initiated, to the maximal extent. On the other hand, the unconstrained optimal security is concave, which implies that the information in all states is not equally valuable to the entrepreneur. In particular, more precise information is less valuable to the entrepreneur in a higher state than in a lower state. The intuition here is also clear. For a lower state, a given amount of additional information would significantly improve the posterior of the investor, which encourages her to make the decision of acceptance that is in favor of the entrepreneur. For a higher state, however, the same amount of additional information would be less valuable, because the higher state is already enough attractive to the investor given her prior, and thus a more precise posterior would not add much. In other words, it would not affect the probability of acceptance too much if the investor has less precise information for higher states, if she is confident enough by acquiring sufficiently precise information for the lower states. As a consequence, it is desirable for the entrepreneur to reduce the share to the investor in higher states. By doing this, the entrepreneur not only grasps a considerable share of the project's future cash flow, but also gives the investor enough and efficient incentives to acquire information that is favorable to the entrepreneur.

Having characterizing the unconstrained optimal security $\widehat{s}(\theta)$, we bring in the feasibility 
constraints $0 \leqslant s(\theta) \leqslant \theta$ and analyze the actual optimal security $s^{*}(\theta)$. It is instructive to have the following lemma to illustrate the possible relative positions between the unconstrained optimal security and the feasibility constraints.

Lemma 3. Three possible relative positions between the unconstrained optimal security $\widehat{s}(\theta)$ and the feasibility constraints $0 \leqslant s(\theta) \leqslant \theta$ may occur in equilibrium, in the $\theta \sim s$ space:

i). $\widehat{s}(\theta)$ intersects with the $45^{\circ}$ line $s=\theta$ at $(\widehat{\theta}, \widehat{\theta}), \widehat{\theta}>0$, and does not intersect with the horizontal axis $s=0$.

ii). $\widehat{s}(\theta)$ goes through the origin $(0,0)$, and does not intersect with either the $45^{\circ}$ line $s=\theta$ or the horizontal axis $s=0$ for any $\theta \neq 0$.

iii). $\widehat{s}(\theta)$ intersects with the horizontal axis $s=0$ at $(\widetilde{\theta}, 0), \widetilde{\theta}>0$, and does not intersect with the $45^{\circ}$ line $s=\theta$.

In the three different cases, it is easy to imagine that the actual optimal security $s^{*}(\theta)$ will be constrained by the feasibility condition in different ways. For example, the optimal security will be constrained by the $45^{\circ}$ line $s=\theta$ in case i) and by the horizontal axis $s=0$ in case iii). Our concern is whether the presence of the two feasibility constraints would significantly change the interplay between security design and information acquisition, and thus the resulting optimal security. Fortunately, the answer is no. As expected, the feasibility constraints are only mechanical. By imposing the feasibility conditions, we have the following characterization for the optimal security:

LEMMA 4. In an equilibrium with information acquisition, the corresponding optimal security $s^{*}(\theta)$ satisfies

$$
s^{*}(\theta)=\left\{\begin{array}{ccc}
\theta & \text { if } & \widehat{s}(\theta)>\theta \\
\widehat{s}(\theta) & \text { if } & 0 \leqslant \widehat{s}(\theta) \leqslant \theta \\
0 & \text { if } & \widehat{s}(\theta)<0
\end{array}\right.
$$

where $\widehat{s}(\theta)$ is the corresponding unconstrained optimal security.

Lemma 4 is important because it tells us how to construct an optimal security with information acquisition from its corresponding unconstrained optimal security. Concretely, the optimal security $s^{*}(\theta)$ will follow its corresponding unconstrained optimal security $\widehat{s}(\theta)$ when the latter is within the feasible region $0 \leqslant s \leqslant \theta$. When the unconstrained optimal security is out of the feasible region, the resulting optimal security will follow one of the feasibility constraints that is binding. The expression of Lemma 4 is fairly simple but the result is not trivial. Importantly, the presence of the feasibility constraints indeed changes the shapes of the resulting optimal securities from its unconstrained counterparts, which implies that the investor's incentives of information acquisition is also changed. Nevertheless, Lemma 4 ensures us that such change does not affect 
the entrepreneur's choice of the cash flow allocations in the states where the feasibility constraints are not binding. Also, in the states where the feasibility constraints are binding, Lemma 4 tells us that it is still optimal for the entrepreneur to just hit the binding constraints to exploit the investor's information advantage to the largest extent.

Therefore, we can apply Lemma 4 to the three cases of the unconstrained optimal security $\widehat{s}(\theta)$ described in Lemma 3 . This gives the three potential cases of the optimal security $s^{*}(\theta)$, respectively.

LEMma 5. In an equilibrium with information acquisition, the optimal security $s^{*}(\theta)$ may take one of the following three forms:

i). When the corresponding unconstrained optimal security $\widehat{s}(\theta)$ intersects with the $45^{\circ}$ line $s=\theta$ at $(\widehat{\theta}, \widehat{\theta}), \widehat{\theta}>0$, we have

$$
s^{*}(\theta)=\left\{\begin{array}{ccc}
\theta & \text { if } & 0 \leqslant \theta<\widehat{\theta} \\
\widehat{s}(\theta) & \text { if } & \theta \geqslant \hat{\theta}
\end{array} .\right.
$$

ii). When the corresponding unconstrained optimal security $\widehat{s}(\theta)$ goes through the origin $(0,0)$, we have $s^{*}(\theta)=\widehat{s}(\theta)$ for $\theta \in \mathbb{R}_{+}$.

iii). When the corresponding unconstrained optimal security $\widehat{s}(\theta)$ intersects with the horizontal axis $s=0$ at $(\widetilde{\theta}, 0), \widetilde{\theta}>0$, we have

$$
s^{*}(\theta)=\left\{\begin{array}{ccc}
0 & \text { if } & 0 \leqslant \theta<\widetilde{\theta} \\
\widehat{s}(\theta) & \text { if } & \theta \geqslant \widetilde{\theta}
\end{array} .\right.
$$

We illustrate the three cases of optimal securities $s^{*}(\theta)$ in the following graph.
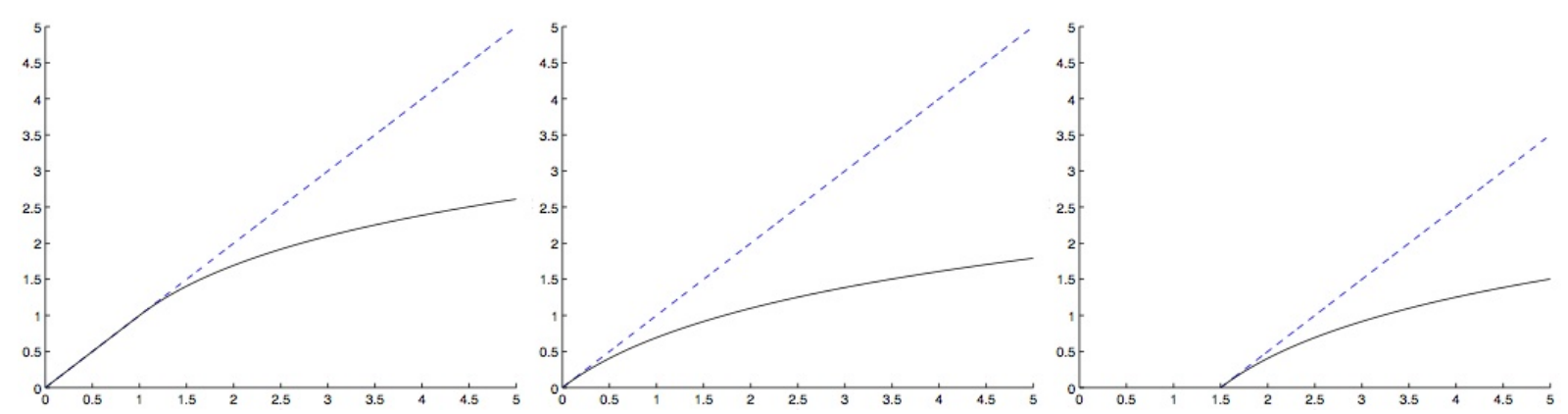

Figure 2: Potential Shapes of the Optimal Contracts

The three potential cases of the optimal security $s^{*}(\theta)$ take different shapes. Specifically, in case i), the optimal security follows a standard debt in bad states but increases as a concave function in good states. In case iii), the payment of optimal security in bad states is zero, while is an increasing and concave function in good states. Case ii) lies in between as a cut-off case, in which the payment of optimal security is an increasing and concave function. 
Having characterizing the potential cases of the optimal security $s^{*}(\theta)$ by its differential properties, we proceed by checking whether these three potential cases are indeed the valid solution to the entrepreneur's problem in an equilibrium with information acquisition. Interestingly, not all the three cases can occur in equilibrium. The following proposition tells us that only the optimal security in case i) can actually sustain an equilibrium with information acquisition.

Proposition 4. If the entrepreneur's optimal security $s^{*}(\theta)$ induces the investor to acquire information in equilibrium, then it must follow case i) in Lemma 5, which corresponds to a (participating) convertible preferred stock with a face value $\widehat{\theta}$.

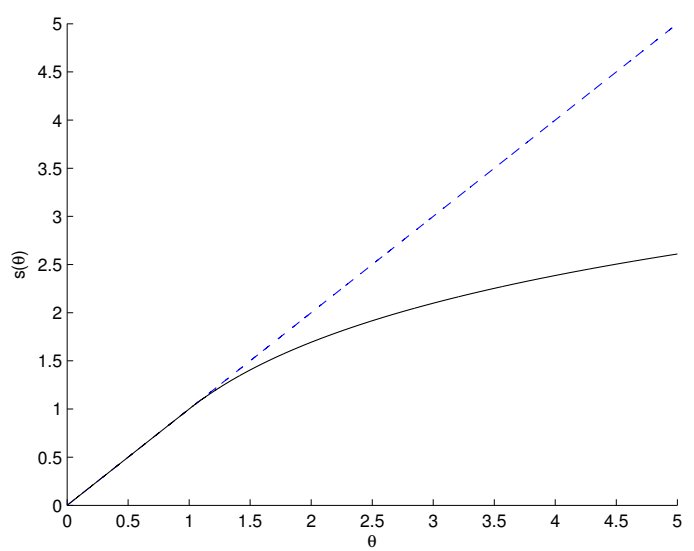

Figure 3: The Unique Optimal Contract with Information Acquisition

The underlying intuition for us to rule out the last two potential cases of the optimal security is consistent with the practice of finance in reality. Recall that the investor can always reject the offer and enjoy her outside option, which is normalized to zero in the context, if her expected payoff is negative. The rejection of the security, however, is always sub-optimal to the entrepreneur, as long as the project has a positive expected future cash flow. As a result, the entrepreneur wants to make sure that the investor, who makes the initial investment and takes cost to acquire information, is sufficiently compensated so that she is willing to accept the security. The last two cases described in Lemma 5 corresponds to the scenarios in which the investor is not enough compensated so that the security is rejected. To link this intuition to the real-world practice, because new technologies often involve considerable intangible parts and high uncertainty, investors often ask for a large amount of compensations in bad states for a downside protection, in terms of the cash flow rights. Actually, the last two cases in Lemma 5 look closest to the common stock, which is the least used security between entrepreneurs and investors in real-world venture finance cases (Kaplan and Stromberg, 2003; Kaplan and Lerner, 2010; Lerner, Leamon and Hardymon, 2012).

In particular, Proposition 4 offers a very specific prediction on the entrepreneur's optimal securities which may be employed in financing risky projects. Specifically, the optimal security 
follows a debt in bad states until its face value and still increases in good states, which corresponds to a convertible preferred stock. In particular, it is closet to the participating convertible preferred stock, which grants the holder a right to receive both the face value and their equity participation as if the stock were converted, in the event of a sale or liquidation. This is consistent with the empirical evidences of venture capitalist contracts, in which the convertible preferred stock accounts for $79.8 \%$ of total contracts used, and $48.2 \%$ of them are participating (Kaplan and Stromberg, 2003). This clear prediction cannot be achieved by classic models that are silent on the information expertise of investors. For simplicity, we will refer to the optimal security in this case as the convertible preferred stock in what follows.

Theoretically, Proposition 4 also displays a clear relationship between security design and information acquisition, as we highlighted throughout the paper. The optimal securities not only reflects that the entrepreneur wants to design such a security that the investor is willing to acquire more information to help distinguish between good states and bad states, but also characterizes the detailed information acquired by the investor in financing the project. A more significant change of the slope of the security at a given point implies that more information about the future cash flow $\theta$ is acquired around that point of the entire distribution. As we mentioned above, the basic relationship between security design and information acquisition is unaffected when our focus switches from the unconstrained optimal security to the actual optimal security.

It is again interesting to contrast the results here to Yang (2012a), where the optimal security is always a debt. As the seller's asset is already in-place in Yang (2012a), the aggregate risk is fixed regardless of the consequence of liquidity provision. Hence, information acquisition is socially wasteful in that case. Concretely, liquidity provision with fixed aggregate risk leads to conflicting interests of the two parties, so that the information acquired by the buyer makes herself better off but at the expense of the seller through endogenous adverse selection. As a result, the seller designs the debt to optimally discourage information acquisition harmful to her own interests. In contrast, in the circumstance of finance in a production economy, the entrepreneur and the investor jointly expose themselves to an aggregate risk if the investor accepts the security and finances the project, and are not exposed to such risk if the security is rejected. In this case, information acquisition could be socially valuable and the conflicting interests of the two parties could be partly reconciled. In other words, adverse selection is no longer the focus in the finance of risky projects in a production economy. Therefore, the entrepreneur could design a security to encourage the investor to acquire information that helps to screen in good projects. This comparison also sheds lights on the different implications of liquidity provision between a production economy (or a primary financial market) and an exchange economy (or a secondary financial market). In a production economy (or a primary financial market), liquidity provision affects the aggregate risk; while in an exchange economy (or a secondary financial market) the 
aggregate risk is irrelevant of liquidity provision. Therefore, when liquidity provision involves information acquisition, different economies (or financial markets) may require different forms of optimal securities, because the incentives of information acquisition and the underlying values of information in different circumstances are different accordingly.

For the convertible preferred stock as the optimal security, the following proposition gives us more confidence in terms of its consistency with the empirical evidences. It concerns about the multiple of the resulting convertible preferred stock, which is defined as the ratio of the face value $\widehat{\theta}$ of the convertible preferred stock and the investor's initial investment $k$. The multiple is viewed as a key characteristic of a convertible preferred stock, which is similar to the role of returns.

Proposition 5. The multiple of the convertible preferred stock, as the optimal security $s^{*}(\theta)$ that induces information acquisition in equilibrium, is greater than one. In other words, $\widehat{\theta}>k$.

Proposition 5 identifies that the multiple of the convertible preferred stock is greater than 1 , which is consistent with the empirical documents (Kaplan and Stromberg, 2003; Lerner, Leamon and Hardymon, 2012). In practice, the multiple would always be greater than one to ensure the investors' keen interest in converting when they exit. In our context, this property still comes from the logic that the investor should be sufficiently compensated to be willing to pay the costs of physical investment as well as information acquisition. Although we do not explicitly model the exiting of investors in our model, we incorporate the consequence of exiting in the distribution of the future cash flow. Hence, the correct prediction of the multiple offers us another perspective to assess the power of our model.

\subsection{The Optimal Securities: A New Pecking Order}

We proceed by taking together the two cases discussed above and link them to some fundamental features of the production economy, which also allows us to deliver new insights regarding the celebrated pecking order theory (Myers and Majluf, 1984) in the presence of production and information acquisition. As we have characterized in the two subsections above, the investor may either accept the security with probability one and acquire no information, or accept it with positive but less than one probability and acquire information. The former case corresponds to the standard debt as the optimal security, while the latter case corresponds to the convertible preferred stock. We try to separate these two cases according to some exogenous parameters in the production economy. This helps to fix how the optimal security is shaped by the dependence of the real production and information production.

The next proposition tells that the only security to finance a project with a negative standard expected NPV is the convertible preferred stock, which induces the investor to acquire information. In other words, a project with a negative standard expected NPV can never be financed 
by a standard debt that does not induce information acquisition, which is consistent with the traditional wisdom of the standard expected NPV criterion, where the beliefs are taken as given and fixed. Nevertheless, as we have seen in Proposition 2, some projects with negative expected NPV can also be financed with positive probability. The next proposition clarifies the point: the finance of negative expected NPV projects is made possible only by information acquisition and belief updating. In this sense, we challenged the traditional NPV criterion of investment by offering a new unified criterion, highlighting the perspective of information acquisition.

Proposition 6. When the project is financed with positive probability, namely, condition (3.1) in Proposition 2 is satisfied:

i). If $\mathbb{E}[\theta]-k>0$, the optimal security $s^{*}(\theta)$ is either a convertible preferred stock as characterized in case i) of Lemma 5, or a standard debt, as characterized in Proposition 3; or

ii). If $\mathbb{E}[\theta]-k \leqslant 0$, the optimal security $s^{*}(\theta)$ is a convertible preferred stock as characterized in case i) of Lemma 5.

From a first look, Proposition 6 is not a strong statement as it does not fully distinguish between the two possible optimal securities, namely, the standard debt and the convertible preferred stock. Nevertheless, it is a strong result. Again, recall that the key condition involved in Proposition 6 is the standard expected NPV $\mathbb{E}[\theta]-k$. In case i), when the standard expected NPV is positive, it already yields a positive social surplus to finance the project without any information acquisition, so that to acquire costly information is less worthwhile for the production economy. In other words, the dependence of real production on information production is weaker. As a result, the optimal security in this case may be the standard debt, although there are still some chances that the convertible preferred stock is used as the optimal security to encourage information acquisition. On the contrary, in case ii), when the project has a zero or negative standard expected NPV, it is always not socially efficient to finance it ex-ante. The only way to deliver a positive social surplus is to screen good projects by information acquisition. Hence, the dependence of real production on information production is stronger, and thus the optimal security turns out to be the convertible preferred stock for sure in order to encourage information acquisition. Clearly, the potential value of information in the two cases are different. This point will be displayed in a clearer way when we perform the comparative statics and welfare analysis below. We would see that Proposition 6 indeed provides a solid foundation for us to deliver meaningful comparative statics and welfare analysis.

We can pursue the spirit of Proposition 6 further to fully distinguish between the two optimal securities with respect to exogenous model parameters. Unfortunately, we are unable to deliver an analytical condition now, but we can offer numerical examples to illustrate the idea. Here we perform a typical one. 
The following numerical example allows us to speak to a new pecking order theory of optimal securities. For some given prior distributions of $\theta$, the fundamental of the risky project, we compare the optimal securities within a set of $(k, \mu)$ pairs, namely the investment requirement and the information cost. We pick up four distributions of $\theta$ with the same mean but increasing risks. Specifically, we take normal distributions with mean 0.5 and a series of standard deviation $0.125,0.25$, and 2 , and then truncate these distributions to interval $[0,1]$. The family also consists of a fourth distribution which represents an extreme case, in which the project is so riskier that it has more chances to take either a best-case realization or a worst-case realization. In other words, the fourth extreme distribution is a mean-preserving spread of the first three distributions. All the distributions are normalized after the truncation. We illustrate the family of four distributions in Figure 4. As for the set of $(k, \mu)$ pairs, our $k$ varies within the unit interval $[0,1]$ and $\mu$ varies within the unit interval $[0.2,1.2]$.

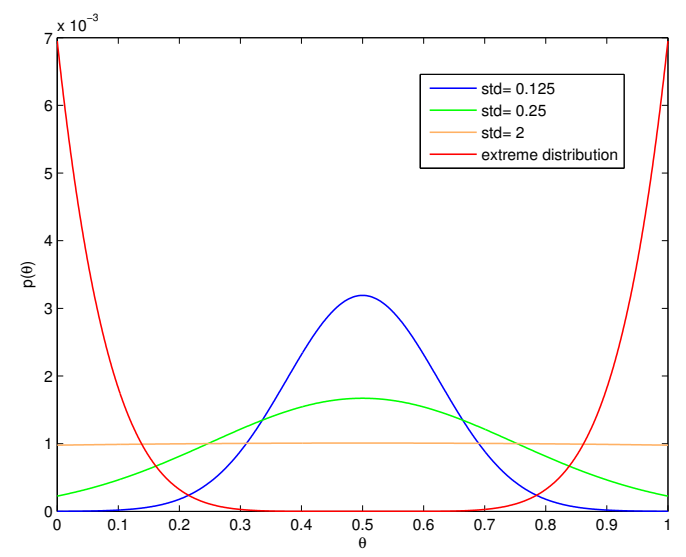

Figure 4: Typical Distributions with Increasing Risks

Together with the characterization of the two non-trivial optimal securities in the previous two cases (without and with inducing information acquisition when trade happens), Proposition 1 allows us to map the two optimal securities to the associated probabilities of trade in their corresponding equilibria. Specifically, when the optimal security is the standard debt, the probability of trade is 1 , while the probability of trade is between 0 and 1 when the optimal security is the convertible preferred stock. When the project is directly rejected without inducing information acquisition, the optimal security is a trivial one. Therefore, we can plot the equilibrium probability of trade against the $(k, \mu)$ pairs within the unit square $[0,1] \times[0.2,1.2]$. The following Figure 5 illustrates how the type of optimal security evolves according to the changes of investment requirement, information cost, as well as the risk of the project. These results construct a new pecking order of securities. 

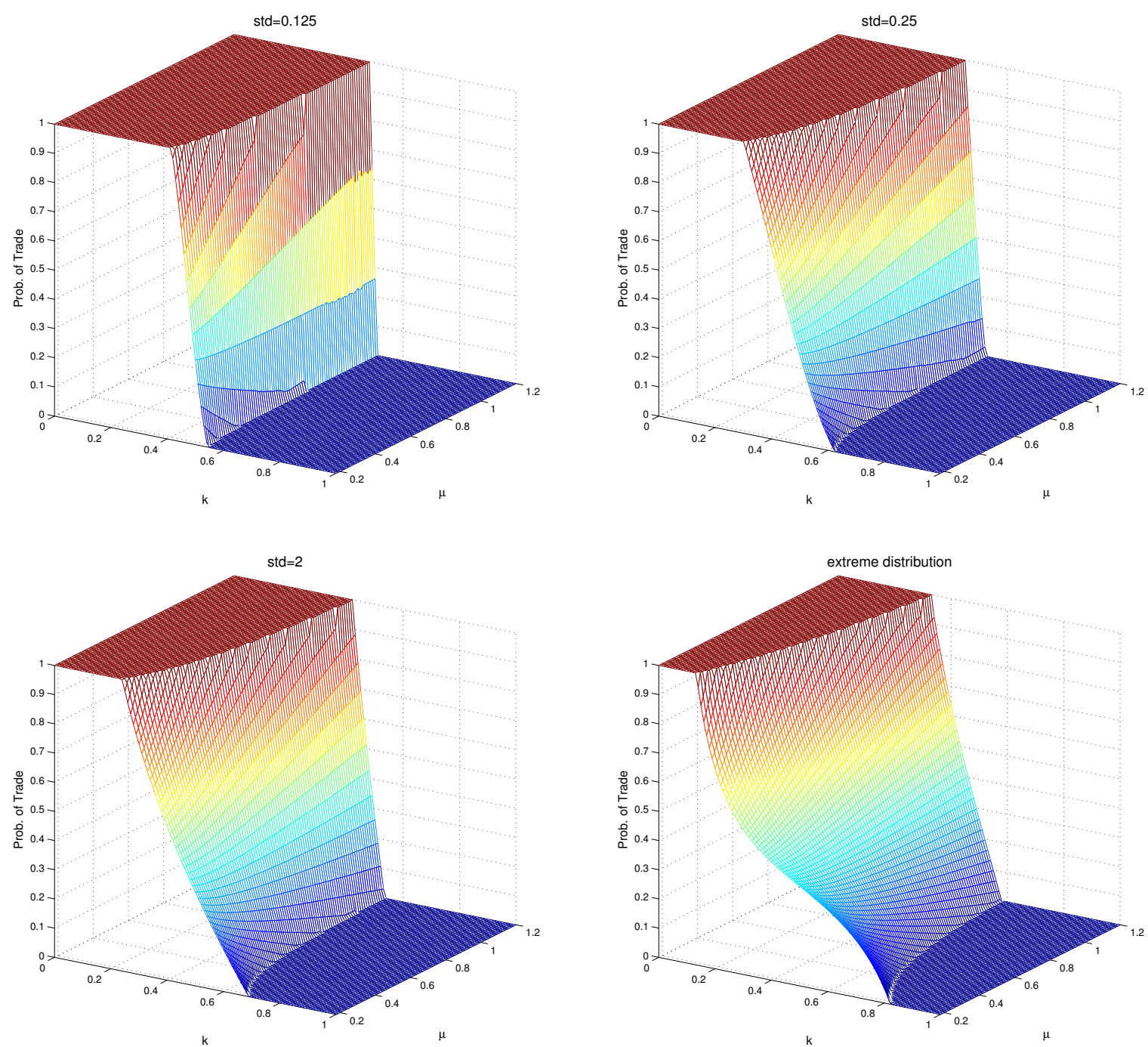

Figure 5: Pecking Order of Optimal Securities

The pecking order of optimal securities is displayed in Figure 5 as the evolution from the red upper platform to the rainbow-colored cliff then to the dark blue lower platform. Concretely, the upper platform consists of equilibria in which the probability of trade is 1 , which implies the underlying optimal security is the standard debt. The cliff consists of equilibria in which the probabilities of trade are numbers between 0 and 1 , which implies the underlying optimal security is the convertible preferred stock. The lower platform represents the equilibria in which the project is rejected for sure without inducing information acquisition and the optimal security is trivial.

We interpret the new pecking order of optimal securities within our framework of production economy with information acquisition, and again we focus on the first two cases with non-trivial optimal securities when trade happens. First, given other parameters fixed, when the investment requirement $k$ increases, the optimal security evolves from the standard debt to the convertible 
preferred stock. Intuitively, the larger $k$ is, the less attractive the project looks initially to the investor who is able to screen it by information acquisition, so that the real production depends more heavily on the information production and information acquisition is more worthwhile. Therefore, it is more desirable for the entrepreneur to propose a convertible preferred stock to encourage the investor to acquire information and thus to increase the odds at which the project could be financed.

Second, given other parameters fixed, there is also a larger chance for the convertible preferred stock to be optimal when the risk of the project is larger. The intuition here is similar to the earlier case regarding the investment requirement $k$. When the prior risk of the project is higher, the project is less attractive to the investor at the first place, so that information acquisition is more worthwhile. This is again consistent with the intuition that the dependence of real production on information production matters for the optimal security.

Last, given other parameters fixed, the optimal security evolves from the convertible preferred stock to the standard debt when the information cost $\mu$ gets larger. In this case, the dependence of real production on information production is fixed, which means the benefit of information acquisition is unchanged. As a result, whether information acquisition is worthwhile or not relies on the cost of information acquisition. When the cost of information acquisition is higher, it is less likely that the benefit from information acquisition would justify the information cost. So it turns out the convertible preferred stock that encourages information acquisition is less likely to be used. If the project has a positive expected NPV ex-ante, it is more likely that the investor would finance the project directly with the standard debt. Otherwise, it is also more likely that the project would be rejected directly.

\section{Comparative Statics of the Optimal Security}

In this section, we proceed further to discuss the evolution of the shape of optimal securities when the nature of the underlying project and the information cost of the investor varies. As we emphasize throughout the paper, security design and information acquisition are closely interplayed in the context. When the parameters of the environment vary, the way though which the entrepreneur would like to follow to take advantage of the investor's information expertise also changes. This eventually leads to different shapes of optimal security in equilibrium.

We unify the intuitions of all the comparative statics. Conflicting interests present between the entrepreneur and the investor, because they share the total surplus of the production economy in our context. Nevertheless, the conflict could be partly alleviated by increasing the social plus, which is done by costly information acquisition that help screen in good projects. Consequently, a natural tension, consisting of two competing forces, faces the entrepreneur when she proposes 
the security. On the one hand, as only the investor is able to acquire information, which is helpful in standing out good projects, the entrepreneur would like to compensate the investor more generously in order to encourage information and thus elevates the total surplus. On the other hand, however, as the entrepreneur's utility is the opposite of the proposed security, she would like to keep more and share less with the investor as long as the investor would not reject the offer. When the first force gets more powerful, the resulting optimal security would move closer to the $45^{\circ}$ line, which encourages information acquisition to the greatest extent, and leaves the least to the entrepreneur. In contrast, when the second force dominates, the resulting optimal security would move closer to a standard debt, which encourages information acquisition to the least extent and leaves the most to the entrepreneur. This idea will be demonstrated in a more formal way in our welfare analysis.

\subsection{Scale of Venture Project}

First, we consider the effect of changing the initial investment $k$ on the optimal security $s^{*}(\theta)$. In doing this, we fix the market prospect of the project as well as the investor's information cost. Concretely, we fix the distribution of $\theta$ and the value of $\mu$. When the nature of the project is fixed, a decrease in the initial investment represents that the project is more scalable. Roughly, this means the project is more cost-benefit efficient.

We show that, when the project is financed with positive probability, the face value $\hat{\theta}$ of the convertible preferred stock is increasing in the required investment $k$. The cash flows after converting is also increasing in $k$. Moreover, the optimal security will be a standard debt when $k$ is sufficiently small. Intuitively, when the project is more scalable or more cost-benefit efficient, it is more likely to be financed by a standard debt without inducing information acquisition. In contrast, when the project is less scalable or less cost-benefit efficient, it is more likely to be financed by a convertible preferred stock, where information acquisition in induced and the compensation to the investor tends to be higher.

We offer the following numerical simulations to illustrate our result, as shown in Figure 6 . The distribution of $\theta$ is fixed and generated as follows. We take a normal distribution with mean 0.5 and standard deviation 0.125 , and then truncate this distribution to interval $[0,1]$. The information cost $\mu$ is fixed at 0.2 . The initial investment $k$ will be taking five different values: 0.4 , $0.45,0.475,0.5$, and 0.525 . We would see the optimal security as a standard debt when $k=0.4$, and as a convertible preferred stock as described above when $k$ is taking larger values. The left panel illustrates the distribution of $\theta$ we used, and the right panel illustrates the evolution of the optimal security. 

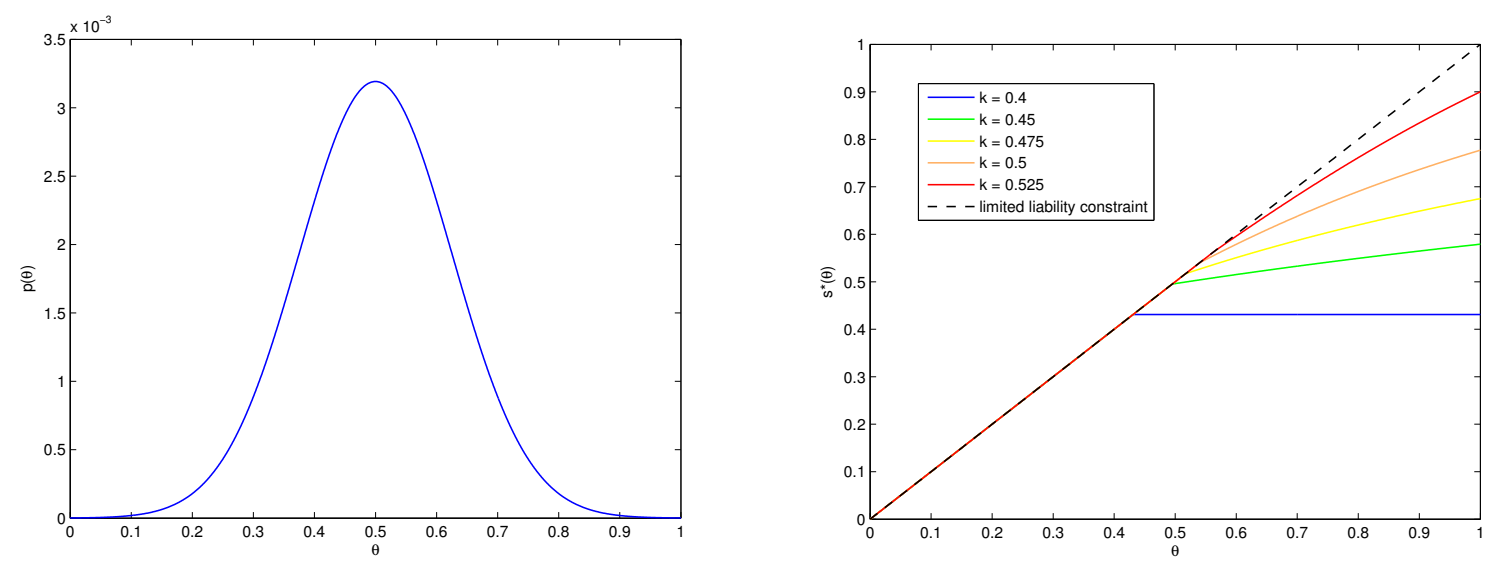

Figure 6: Change of Initial Investment: $\mu=0.2$

The intuition for the comparative statics for the scale of project is clear. When the initial investment $k$ is smaller, the project is more attractive ex-ante, so that it is less desirable to compensate the investor to induce costly information acquisition. In other words, the first force as described, namely, the value of information, decreases. As a result, the resulting security moves towards the standard debt. On the contrary, when the initial investment $k$ is greater, the project is less attractive ex-ante and screening becomes more necessary. Hence, the entrepreneur is more willing to propose a more generous convertible preferred stock to the investor to induce information acquisition.

\subsection{Risk of Venture Project}

We move on to consider the effect of changing the project's risk on the optimal security $s^{*}(\theta)$. Especially, when considering the change of risk, we fix the mean of the priors of the fundamental $\theta$, and consider a family of distributions which are ranked by second order stochastic dominance. In doing this, we also fix the initial investment $k$ of the project as well as the investor's information cost $\mu$. Interestingly, the comparative statics in this case depends largely on the relationship between the mean of the fundamental $\mathbb{E}[\theta]$ and the initial investment $k$, as separated by the two cases in Proposition 6.

First, we consider case i) in Proposition 6 , namely, $\mathbb{E}[\theta]>k$. This implies that the project has a positive standard expected NPV, given the prior. We show that, in this case, the face value $\widehat{\theta}$ of the convertible preferred stock is increasing in the risk of the project. The cash flows after converting is also increasing in the risk. Moreover, the optimal security will be a standard debt when the risk is sufficiently small. Intuitively, when the project is less risky, it is more likely to be financed by a standard debt without inducing information acquisition. In contrast, when the project is riskier, it is more likely to be financed by a convertible preferred stock, where information acquisition is induced and the compensation to the investor tends to be higher. 

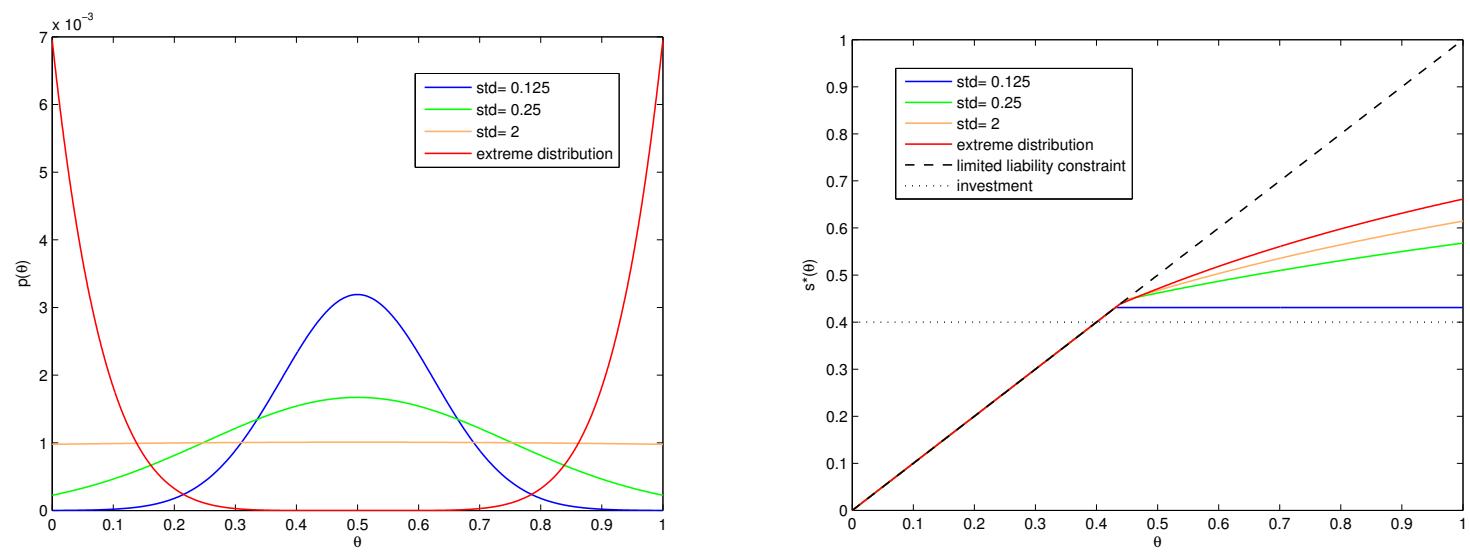

Figure 7: Change of Risk: $k=0.4<\mathbb{E}[\theta]=0.5, \mu=0.2$

We offer the following numerical simulations to illustrate our result, as in Figure 7. The initial investment is fixed at $k=0.4<\mathbb{E}[\theta]$. The information cost $\mu$ is fixed at 0.2 . The families of distributions of $\theta$ are generated as we did in Figure 4. The left panel illustrates the distributions of $\theta$ we used, and the right panel illustrates the evolution of the optimal security.

The intuition for this case is the following. It is worth noting that, the effect of risk changes cannot be accounted by the argument of risk attitude, because both the entrepreneur and the investor in our context is risk neutral. Instead, we still link the change of risk with the tension and the two forces we discussed before. Also, keep in mind that we have $k<\mathbb{E}(\theta)$ in this case, which means the project has a standard positive expected NPV. When the risk of the project is smaller, the prior probability for the project to have a positive NPV is larger, which implies the project is more attractive ex-ante. Hence, similarly, it is less desirable to compensate the investor to induce costly information acquisition. Again, the first force as described, namely, the value of information, decreases. Hence, the resulting security moves towards the standard debt. On the contrary, when the risk is greater, the project is less attractive ex-ante and screening becomes more necessary. Hence, the entrepreneur is more willing to propose a more generous convertible preferred stock to the investor to induce information acquisition.

Then we consider case ii) in Proposition 6 , namely, $\mathbb{E}[\theta] \leqslant k$. This implies that the project has a non-positive standard expected NPV, given the prior. But it would be still financed with positive probability in equilibrium, thanks to screening. In contrast, in this case, the face value $\widehat{\theta}$ of the convertible preferred stock, is decreasing in the risk of the project. The cash flows after converting is also decreasing in the risk. This means, when the project is riskier, the compensation to the investor tends to be lower. 

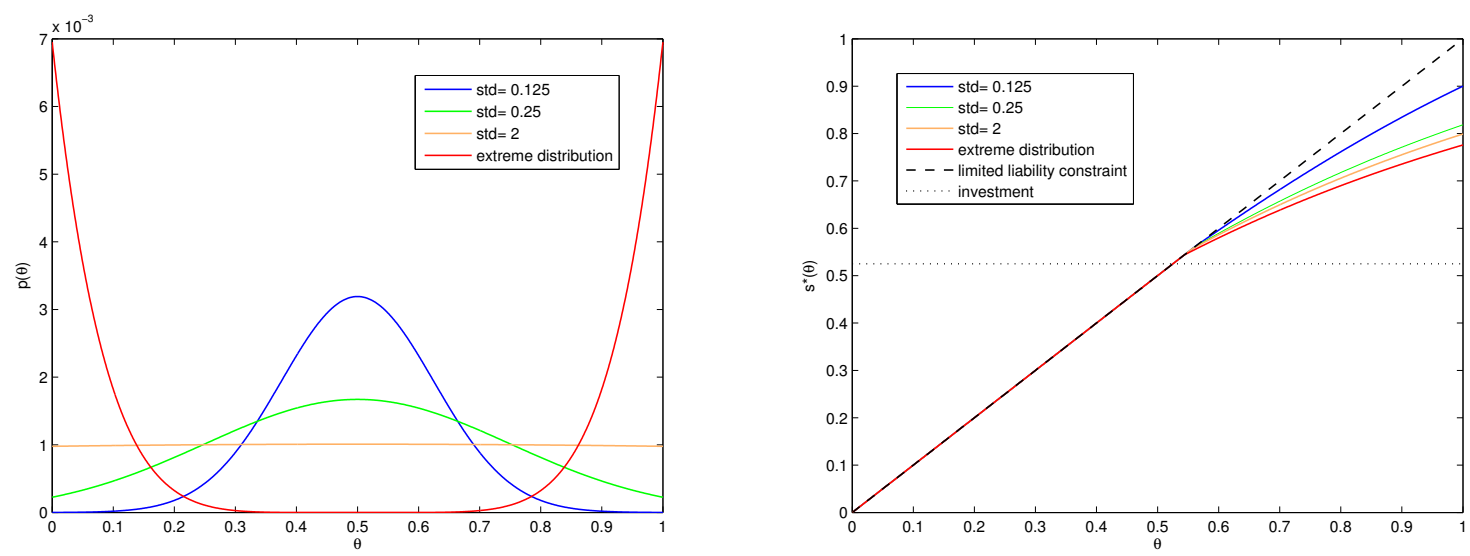

Figure 8: Change of Risk: $k=0.525 \geqslant \mathbb{E}[\theta]=0.5, \mu=0.2$

The numerical simulations are as in Figure 8. The initial investment is fixed at $k=0.525 \geqslant$ $\mathbb{E}[\theta]$ and the information cost $\mu$ is still fixed at 0.2 . Similarly, We take normal distributions with mean 0.5 and a series of standard deviation $0.125,0.25$, and 2 , and then truncate these distributions to interval $[0,1]$. The fourth distribution as an extreme case is still included. All the distributions are normalized after the truncation. Again, the left panel illustrates the distributions of $\theta$ we used, and the right panel illustrates the evolution of the optimal security.

The intuition for this case is similar. Keep in mind that we have $k \geqslant \mathbb{E}(\theta)$ in this case, which means the project has a non-positive expected NPV. In contrast to the previous case, when the risk of the project is smaller, the prior probability for the project to have a positive NPV is also smaller instead, which implies the project is less attractive ex-ante. This means the first force, namely, the value of information increases. Hence, the entrepreneur is more willing to propose a more generous convertible preferred stock to the investor to induce information acquisition. Rather, when the risk is greater, the project is indeed more attractive ex-ante and screening becomes less necessary, so that the resulting security moves towards the standard debt.

\subsection{Investor's Information Advantage}

Last, we consider the effect of changing the investor's information cost $\mu$ on the optimal security $s^{*}(\theta)$, with the distribution of $\theta$ and the initial investment $k$ fixed. Again, interestingly, the comparative statics in this case depends on the relationship between the mean of the fundamental $\mathbb{E}[\theta]$ and the initial investment $k$, as the two cases in Proposition 6.

First, in case i) of $\mathbb{E}[\theta]>k$, we show that, the face value $\widehat{\theta}$ of the convertible preferred stock, if it is the optimal security in equilibrium, is increasing in the information cost of the project. The concavity of the cash flows after converting is also decreasing in the information cost. Interestingly, the converting rate is always decreasing in the information cost, which means the investor is less compensated in good states, if she has a higher information cost. When the information cost is 
sufficiently large, the investor would not acquire information anymore, and the optimal security would be a standard debt, with a higher face value.

In the numerical simulations as in Figure 9, the initial investment is fixed at $k=0.4<\mathbb{E}(\theta)$. The distribution of $\theta$ is also fixed and generated as follows. We take a normal distribution with mean 0.5 and standard deviation 2 , and then truncate this distribution to interval $[0,1]$. The information cost $\mu$ will be taking four different values: $0.2,0.4,0.6$, and 1 . The left panel illustrates the distribution of $\theta$ we used, and the right panel illustrates the evolution of the optimal security.
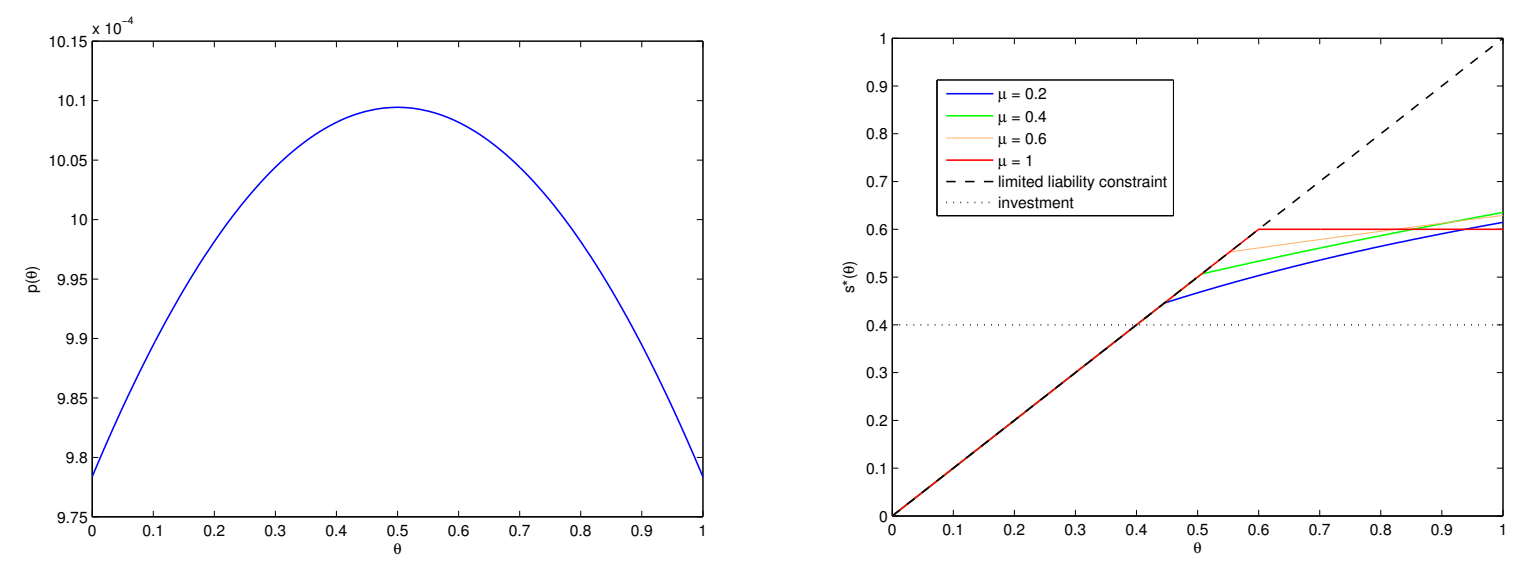

Figure 9: Change of Information Cost: $k=0.4<\mathbb{E}[\theta]=0.5$

The intuition for this case is as follows. We have $k<\mathbb{E}(\theta)$ in this case, which means the project has a standard positive expected NPV. This implies that information is not that valuable to the entrepreneur in this case. When the investor's information cost becomes larger, it is harder for the entrepreneur to make the investor accept the offer. Hence, the entrepreneur has to give up more to the investor by raising the face value of the proposed security. Moreover, as information is not so valuable, the entrepreneur would like to encourage less information acquisition by proposing flatter cash flows in good states, which help lower the investor's information cost in equilibrium. As a result, the cash flows after converting would become less in this case.

Then we consider case ii) of $\mathbb{E}[\theta] \leqslant k$. We show that, the face value $\widehat{\theta}$ of the convertible preferred stock is still increasing in the information cost of the project, and the concavity of the cash flows after converting is also decreasing in the information cost. Nevertheless, the converting rate is always increasing in the information cost, which means the investor is more compensated in good states, if she has a higher information cost. 

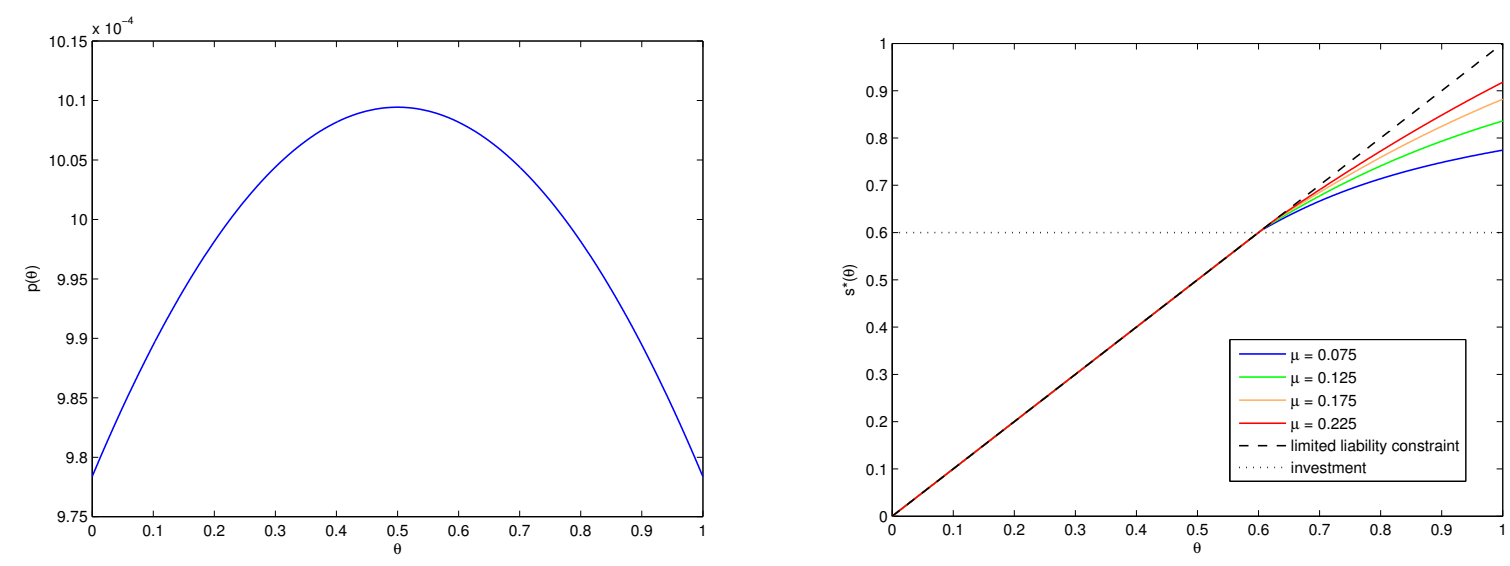

Figure 10: Change of Information Cost: $k=0.6 \geqslant \mathbb{E}[\theta]=0.5$

The numerical simulations are as Figure 10. The initial investment is fixed at $k=0.6 \geqslant \mathbb{E}(\theta)$. The distribution of $\theta$ is also fixed and generated as follows. Again, we take a normal distribution with mean 0.5 and standard deviation 2 , and then truncate this distribution to interval $[0,1]$. Similarly, The information cost will be taking four different values: 0.075, 0.125, 0.175, and 0.225. Again, the left panel illustrates the distribution of $\theta$ we used, and the right panel illustrates the evolution of the optimal security.

The intuition for this case is straightforward under our unified explanation. Recall we have $k \geqslant \mathbb{E}(\theta)$ in this case, which means the project has a non-positive expected NPV. This implies that information is very valuable to the entrepreneur in this case. When the investor's information cost becomes larger, it is harder for the entrepreneur to make the investor accept the offer, so that the entrepreneur has to offer more. Especially, as information is very valuable in this case, the entrepreneur wants to encourage more information acquisition by proposing more cash flows after converting to compensate for the investor's higher information cost.

\section{Social Welfare Analysis}

In this section, we perform social welfare analysis that further helps to uncover the relationship between information acquisition and security design. First, we consider a centralized economy, where security design is irrelevant. The centralized economy benchmarks previous results of security design as well as the associated rules of information acquisition against a first-best information acquisition. Then, we return to the decentralized production economy and investigate the optimal security, where a social planner designs the security to maximize an weighted average of the entrepreneur's and the investor' payoff gains. The latter case also speaks to different allocations of bargain powers between the entrepreneur and the investor and illustrates how such difference shapes optimal security design and information acquisition. 


\subsection{First-Best Information Acquisition without Security Design}

(To be completed.)

\subsection{Constrained First-Best and Allocation of Bargaining Powers}

This section extends our benchmark model to a more general setting which incorporates the allocation of the bargaining powers between the entrepreneur and the investor in the process of security design. Suppose there is a third party in the economy who knows the relative bargaining powers of the entrepreneur and the investor. The entrepreneur's bargaining power in security design is $1-\alpha$ and the investor's is $\alpha$. The third party designs the security and proposes it to the investor. The investor acquire information according to the security she gets and decides whether or not to accept this security. The third party's objective function is a weighted average of the entrepreneur's and the investor's utilities. The weights are the bargaining powers of the two, respectively. When $\alpha=0$, this reduces to our benchmark model.

In this setting, the third-party's objective function, namely, the payoff gain is

$$
u_{T}(s(\theta))=\alpha \cdot(\mathbb{E}[(s(\theta)-k) \cdot m(\theta)]-\mu \cdot I(m))+(1-\alpha) \cdot \mathbb{E}[(\theta-s(\theta)) \cdot m(\theta)] .
$$

We show that, the differential equation that governs information acquisition is still as same as condition (3.6):

$$
s(\theta)-k=\mu \cdot\left(g^{\prime}\left(m_{s}(\theta)\right)-g^{\prime}\left(\bar{p}_{s}\right)\right),
$$

while the other differential equation that characterizes the optimality of the unconstrained security is given as

$$
r(\theta)=(2 \alpha-1) \cdot m(\theta)+(1-\alpha) \cdot \mu^{-1} \cdot m(\theta) \cdot(1-m(\theta)) \cdot(\theta-s(\theta)+w) .
$$

We have the following two propositions to characterize the optimal security in the general setting.

Proposition 7. When $1 / 2 \leqslant \alpha \leqslant 1$, the optimal security features $s^{*}(\theta)=\theta$, which means the investor takes over.

Proposition 8. When $0 \leqslant \alpha<1 / 2$ and information acquisition happens in equilibrium, the unconstrained optimal security $\widehat{s}(\theta)$ and the corresponding information acquisition rule $\widehat{m}_{s}(\theta)$ satisfy

$$
\frac{\partial \widehat{s}(\theta)}{\partial \theta}=\frac{1-\widehat{m}_{s}(\theta)}{1-\frac{\alpha}{1-\alpha} \widehat{m}_{s}(\theta)} \in(0,1)
$$

and

$$
\frac{\partial \widehat{m}_{s}(\theta)}{\partial \theta}=\frac{\mu^{-1} \cdot \widehat{m}_{s}(\theta) \cdot\left(1-\widehat{m}_{s}(\theta)\right)^{2}}{1-\frac{\alpha}{1-\alpha} \widehat{m}_{s}(\theta)}>0 .
$$

Also, all the results from Lemma 3 to Lemma 5 and from Proposition 1 to Proposition 6 are kept. 
Our generalized results show that, when the investor has some bargain power in security design but it is still the entrepreneur who dominates, all the qualitative results keep the same. Nevertheless, if the investor dominates, the optimal security would favor the investor to the greatest extent. The latter case looks counterintuitive at a first glance. But it is indeed consistent with our context, in which the ability of information acquisition should also be accounted as a part of the investor's bargaining power. In the benchmark model, the entrepreneur proposes the security but the investor can acquire information, which exhibits a balance of total bargaining powers. Instead, when even the role of proposing the security goes to the investor, the investor is too powerful in the sense of total bargain powers.

\section{Conclusion and Further Research}

(To be completed.) 


\section{References}

Admati, Anat and Pfleiderer, Paul (1994). "Robust Financial Contracting and the Role of Venture Capitalists." Journal of Finance, 49: 371-402.

Aghion, Philippe and Tirole, Jean (1992). "On The Management of Innovation." Quarterly Journal of Economics, 109: 1185-1207.

Bergemann, Dirk and Hege, Ulrich (1998). "Venture Capital Financing, Moral Hazard, and Learning." Journal of Banking and Finance, 22: 703-35.

Berglof, ErIK (1994). "A Control Theory of Venture Capital Finance." Journal of Law, Economics and Organization, 10: 247-67.

Casamatta, Catherine (2003). "Financing and Advising: Optimal Financial Contracts with Venture Capitalists." Journal of Finance, 58(5): 2059-2085.

Chakraborty, Archishman and Yilmaz, Bilge (2011). "Adverse Selection and Covertible Bonds." Review of Economic Studies, 78: 148-175.

Chemmanur, Thomas, Krishnan, Karthik and Nandy, Debarshi (2012). "How Does Venture Capital Financing Improve Efficiency in Private Firms? A Look Beneath the Surface." Review of Financial Studies, forthcoming.

Cremer, Jacques and Khalil, Fahad (1992). "Gathering Information Before Signing a Contract." American Economic Review, 82: 566-578.

Cremer, Jacques, Khalil, Fahad and Rochet, Jean-Charles (1998a). "Strategic Information Gathering before a Contract Is Offered." Journal of Economic Theory, 81: 163-200.

Cremer, Jacques, Khalil, Fahad and Rochet, Jean-Charles (1998b). "Contracts and Productive Information Gathering." Games and Economic Behavior, 25: 174-193.

Cornelli, Francesca and Yosha, Oved (2003). "Stage Financing and the Role of Convertible Securities." Review of Economic Studies, 70: 1-32.

Da Rin, Marco, Hellmann, Thomas and Puri, Manju (2011). "A Survey of Venture Capital Research." Forthcoming in George Constantinides, Milton Harris, and Rene Stulz (eds), Handbook of the Economics of Finance, 2.

Dang, Tri Vi, Gorton, Gary and Holmstrom, Bengt (2011). "Ignorance and the Optimality of Debt for Liquidity Provision." Working paper. http://sloanweb.mit.edu/finance/pdf/Gary\%20Gorton. pdf

de Bettignies, Jean-Etienne (2008). "Financing the Entrepreneurial Venture." Management Science, 54: $151-166$. 
DeMarzo, Peter and Duffie, Darrell (1999). "A Liquidity-Based Model of Security Design." Econometrica, 67: 65-99.

DeMarzo, Peter (2005). "The Pooling and Tranching of Securities: A Model of Informed Intermediation." Review of Financial Studies, 18: 1-35.

Dow, James, Goldstein, Itay and Guembel, Alexander (2011). "Incentives for Information Production in Markets where Prices Affect Real Investment." Working Paper. http://finance. wharton. upenn. edu/ itayg/Files/informationproduction.pdf

Evans, David and Jovanovic, Boyan (1989). "An Estimated Model of Entrepreneurial Choice under Liquidity Constraints." Journal of Political Economy, 97: 808-827.

Fulghieri, Paolo and Lukin, Dmitry (2001). "Information Production, Dilution Costs, and Optimal Security Design." Journal of Financial Economics, 61: 3-42.

Fulghieri, Paolo, Garcia, Diego and Hackbarth, Dirk (2012). "Asymmetric Information and the Pecking Order." Working Paper. http://public.kenan-flagler.unc.edu/faculty/fulghiep/ Fulghieri-Garcia-Hackbarth-Nov22.pdf

Gorton, Gary and Pennacchi, George (1990). "Financial Intermediaries and Liquidity Creation." Journal of Finance, 45: 49-72.

Hellmann, Thomas (1998). "The Allocation of Control Rights in Venture Capital Contracts." RAND Journal of Economics, 29: 57-76.

Hellmann, Thomas (2006). "IPOs, Acquisitions, and the Use of Convertible Securities in Venture Capital." Journal of Financial Economics, 81: 649-679.

Hennessy, Christopher (2009). "Security Design, Liquidity, and the Informational Role of Prices." Working Paper. http://faculty.london.edu/chennessy/assets/documents/DRAFT18.pdf

Holtz-Eakin, Douglas, Joulfaian, David and Rosen, Harvey (1994). "Sticking It Out: Entrepreneurial Survival and Liquidity Constraints." Journal of Political Economy, 102: 53-75.

Inderst, Roman and Mueller, Holger (2006). "Informed Lending and Security Design." Journal of Finance, 61: 2137-2162.

Innes, Robert (1990). "Limited Liability and Incentive Contracting with Ex-ante Action Choices." Journal of Economic Theory, 52: 45-67.

Kaplan, Steven and Lerner, Josh (2010). "It Ain't Broke: The Past, Present, and Future of Venture Capital." Journal of Applied Corporate Finance, 22: 36-47.

Kaplan, Steven and Stromberg, Per (2003). "Financial Contracting Theory Meets the Real World: An Empirical Analysis of Venture Capital Contracts." Review of Economic Studies, 70: 281-315. 
Kerr, William, Lerner, Josh and Schoar, Antoinette (2011). "The Consequences of Entrepreneurial Finance: Evidence from Angel Financings." Review of Financial Studies, forthcoming.

Kirilenko, Andrei (2001). "Valuation and Control in Venture Finance." Journal of Finance 56: 565-587.

Knight, Frank (1921). Risk, Uncertainty, and Profit. Boston: Houghton Mifflin.

Lerner, Josh, Leamon, Ann and Hardymon, Felda (2012). Venture Capital, Private Equity, and the Financing of Entrepreneurship. John Wiley \& Sons, Inc.

Myers, Stewart and Majluf, Nicholas (1984). "Corporate Financing and Investment Decisions when Firms Have Information that Investors Do Not Have." Journal of Financial Economics, 13: 187-221.

Morris, Stephen and Shin, Hyun Song (1998). "Unique Equilibrium in a Model of Self-Filling Currency Attacks." American Economic Review, 88: 587-597.

Nachman, David and Noe, Thomas (1994). "Optimal Design of Securities under Asymmetric Information." Review of Financial Studies, 7:1-44.

Rajan, Raghu (2012). "Presidential Address: The Corporation in Finance." Journal of Finance, 67: $1173-1217$.

Repullo, Rafael and Suarez, Javier (2004). "Venture Capital Finance: A Security Design Approach." Review of Finance, 8: 75-108.

Scharfstein, David and Stein, Jeremy (2000). "The Dark Side of Internal Capital Markets: Divisional Rent-Seeking and Inefficient Investment." Journal of Finance, 55: 2537-2564.

Schmidt, Klaus (2003). "Convertible Securities and Venture Capital Finance." Journal of Finance, 58:1139-1166.

Schumpeter, Joseph (1942). Capitalism, Socialism, and Democracy. New York: Harper Brothers.

Shannon, Claude (1948). "A Mathematical Theory of Communication." Bell System Technical Journal, 27: $379-423$.

Sims, Christopher (2003). "Implications of Rational Inattention." Journal of Monetary Economics, 50: $665-690$

Stein, JeREmy (1997). "Internal Capital Markets and the Competition for Corporate Resources." Journal of Finance, 52: 111-133.

Townsend, Robert (1979). "Optimal Contracts and Competitive Markets with Costly State Verification." Journal of Economic Theory, 21: 265-293.

VeldKAmp, LAURA (2011). Information Choice in Macroeconomics and Finance. Princeton University Press. 
Woodford, Michael (2008). "Inattention as A Source of Randomized Discrete Adjustment." Working paper. http://www. columbia.edu/ mw2230/Random\%20Discrete\%20Adjustment.pdf

Woodford, Michael (2009). "Information-Constrained State-Dependent Pricing." Journal of Monetary Economics, 56: S100-S124.

YAng, Ming (2012a). "Optimality of Debt with Flexible Information Acquisition." Working paper. http://papers.ssrn.com/sol3/papers.cfm?abstract_id=2103971

YANG, Ming (2012b). "Coordination with Flexible Information Acquisition." http://papers.ssrn.com/ sol3/papers . cfm?abstract_id $=2103970$ 


\section{A Appendix}

This appendix provides all proofs omitted in the main text.

Proof of Proposition 2. We first prove the "only if" part.

Suppose that $\mathbb{E}\left[\exp \left(\mu^{-1}(\theta-k)\right)\right] \leqslant 1$. According to Proposition 1, even if the entrepreneur proposes all the future cash flow to the investor, the investor would reject the offer without acquiring information. Since $s(\theta) \leqslant \theta$, the project cannot be initiated in this case.

Then we prove the "if" part.

Let $t \in(0,1)$. Since $\mathbb{E}\left[\exp \left(\mu^{-1}(t \cdot \theta-k)\right)\right]$ is continuous in $t$, there exists $t<1$ such that

$$
\mathbb{E}\left[\exp \left(\mu^{-1}(t \cdot \theta-k)\right)\right]>1 .
$$

Hence, according to Proposition 1 , the security $s_{t}(\theta)=t \cdot \theta$ would be accepted by the investor with positive probability. Moreover, let $m_{t}(\theta)$ be the corresponding information acquisition rule. As $s_{t}(\theta)$ would be accepted with positive probability, $m_{t}(\theta)$ cannot be always zero. Hence, the entrepreneur's expected payoff is $\mathbb{E}\left[(1-t) \cdot \theta \cdot m_{t}(\theta)\right]$, which is strictly positive.

Note that the security $s_{t}(\theta)$ is a feasible security. Hence, the optimal security $s^{*}(\theta)$ would also be accepted with positive probability and delivers positive expected payoff to the entrepreneur. This concludes the proof.

Proof of Proposition 3. The Lagrangian of the entrepreneur's problem is

$$
\mathscr{L}=\mathbb{E}\left[\theta-s(\theta)+\lambda \cdot\left(1-\exp \left(\mu^{-1} \cdot(k-s(\theta))\right)\right)+\eta_{1}(\theta) \cdot s(\theta)+\eta_{2}(\theta) \cdot(\theta-s(\theta))\right],
$$

where $\lambda, \eta_{1}(\theta)$ and $\eta_{2}(\theta)$ are multipliers.

The first order condition is

$$
\frac{\partial \mathscr{L}}{\partial s(\theta)}=-1+\lambda \cdot \mu^{-1} \cdot \exp \left(\mu^{-1} \cdot(q-s(\theta))\right)+\eta_{1}(\theta)-\eta_{2}(\theta)=0 .
$$

We first consider a special case that is helpful for us to solve the optimal security. If $0<$ $s(\theta)<\theta$, the two feasibility conditions are not binding. Thus $\eta_{1}(\theta)=\eta_{2}(\theta)=0$, and the first order condition is simplified as

$$
-1+\lambda \cdot \mu^{-1} \cdot \exp \left(\mu^{-1} \cdot(k-s(\theta))\right)=0
$$

By rearrangement, we get

$$
s(\theta)=k-\mu \cdot \ln \left(\lambda^{-1} \cdot \mu\right) .
$$

We denote the right hand side of (A.2), which is irrelevant of $\theta$, as $D^{*}$. By definition, we have $D^{*}>0$. Also, it is straightforward to have

$$
-1+\lambda \cdot \mu^{-1} \cdot \exp \left(\mu^{-1} \cdot\left(k-D^{*}\right)\right)=0 .
$$


In what follows, we characterize the optimal solution $s^{*}(\theta)$ for different regions of $\theta$.

First, we consider the region of $\theta>D^{*}$. We show that $0<s^{*}(\theta)<\theta$ in this region by contradiction.

If $s^{*}(\theta)=\theta>D^{*}$, we have $\eta_{1}(\theta)=0$ and $\eta_{2}(\theta) \geqslant 0$. From the first order condition (A.1) we obtain

$$
-1+\lambda \cdot \mu^{-1} \cdot \exp \left(\mu^{-1} \cdot(k-\theta)\right)=\eta_{2}(\theta) \geqslant 0 .
$$

On the other hand, as $\theta>D^{*}$, we have

$$
-1+\lambda \cdot \mu^{-1} \cdot \exp \left(\mu^{-1} \cdot\left(k-D^{*}\right)\right)>-1+\lambda \cdot \mu^{-1} \cdot \exp \left(\mu^{-1} \cdot(k-\theta)\right) .
$$

Conditions (A.3), (A.4), and (A.5) construct a contradiction. So we must have $s^{*}(\theta)<\theta$ if $\theta>D^{*}$.

Similarly, if $s^{*}(\theta)=0$, we have $\eta_{1}(\theta) \geqslant 0$ and $\eta_{2}(\theta)=0$. Again from the first order condition (A.1) we obtain

$$
-1+\lambda \cdot \mu^{-1} \cdot \exp \left(\mu^{-1} \cdot k\right)=-\eta_{1}(\theta) \leqslant 0 .
$$

On the other hand, as $D^{*}>0$, we have

$$
-1+\lambda \cdot \mu^{-1} \cdot \exp \left(\mu^{-1} \cdot\left(k-D^{*}\right)\right)<-1+\lambda \cdot \mu^{-1} \cdot \exp \left(\mu^{-1} \cdot k\right) .
$$

Conditions (A.3), (A.6), and (A.7) construct another contradiction. So we must have $s^{*}(\theta)>0$ if $\theta>D^{*}$.

Therefore, we have shown that $0<s^{*}(\theta)<\theta$ for $\theta>D^{*}$. From the discussion above for the special case, we conclude that $s^{*}(\theta)=D^{*}$ for $\theta>D^{*}$.

We then consider the region of $\theta<D^{*}$. We show that $s^{*}(\theta)=\theta$ in this region.

Since $s^{*}(\theta) \leqslant \theta<D^{*}$, we have

$$
-1+\lambda \cdot \mu^{-1} \cdot \exp \left(\mu^{-1} \cdot\left(k-s^{*}(\theta)\right)\right)>-1+\lambda \cdot \mu^{-1} \cdot \exp \left(\mu^{-1} \cdot\left(k-D^{*}\right)\right) .
$$

From condition (A.3), the right hand side of this inequality (A.8) is zero. Together with the first order condition (A.1), the inequality (A.8) implies that $\eta_{1}(\theta)=0$ and $\eta_{2}(\theta)>0$. Therefore, we have $s^{*}(\theta)=\theta$ in this region.

Also, from the first order condition (A.1) and the condition (A.3), it is obvious that $s^{*}\left(D^{*}\right)=$ $D^{*}$.

To sum up, the entrepreneur's optimal security without inducing the investor to acquire information features a standard debt with face value $D^{*}$ determined by condition (A.2).

Finally, we need to show that there exists $D^{*}>0$ and the corresponding multiplier $\lambda>0$ such that 


$$
\mathbb{E}\left[\exp \left(-\mu^{-1} \cdot\left(\min \left(\theta, D^{*}\right)-k\right)\right)\right]=1
$$

where $D^{*}$ is determined by condition (A.2).

Consider the left hand side of condition (A.9). Clearly, it is continuous and monotonically decreasing in $D^{*}$. When $D^{*}$ is sufficiently large, the left hand side of (A.9) approaches $\mathbb{E}\left[\exp \left(-\mu^{-1} \cdot(\theta-k)\right)\right]$, a number less than one, which is guaranteed by the condition (3.3) as well as the feasibility condition $s(\theta) \leqslant \theta$. On the other hand, when $D^{*}=0$, it approaches $\exp \left(\mu^{-1} \cdot k\right)$, which is strictly greater than one. Hence, there exists $D^{*}>0$ such that the condition (A.9) holds.

Moreover, from the condition (A.2), we also know that $D^{*}$ is continuous and monotonically increasing in $\lambda$. When $\lambda$ approaches zero, $D^{*}$ approaches negative infinity, while when $\lambda$ approaches positive infinity, $D^{*}$ approaches positive infinity as well. Hence, for any $D^{*}>0$ there exists a corresponding multiplier $\lambda>0$. This concludes the proof.

Proof of Lemma 1. We derive the entrepreneur's optimal security $s^{*}(\theta)$ and the corresponding unconstrained optimal security $\widehat{s}(\theta)$ through calculus of variations. Specifically, we characterize how the entrepreneur's expected payoff responds to the perturbation of her optimal security.

Let $s(\theta)=s^{*}(\theta)+\alpha \cdot \varepsilon(\theta)$ be an arbitrary perturbation of the optimal security $s^{*}(\theta)$. Note that the investor's optimal decision rule $m_{s}(\theta)$ appears in the entrepreneur's expected payoff $u_{E}(s(\theta))$, according to condition (3.7), and it is implicitly determined by the proposed security $s(\theta)$ through the functional equation (3.6). Hence, we need first characterize how $m_{s}(\theta)$ varies with respect to the perturbation of $s^{*}(\theta)$. This is given by the following lemma.

Lemma 6. For any perturbation $s(\theta)=s^{*}(\theta)+\alpha \cdot \varepsilon(\theta)$, the investor's decision rule of information acquisition $m_{s}(\cdot)$ is characterized by

$$
\begin{aligned}
\left.\frac{\partial m_{s}(\theta)}{\partial \alpha}\right|_{\alpha=0}= & \mu^{-1} \cdot\left(g^{\prime \prime}\left(m_{s}^{*}(\theta)\right)\right)^{-1} \varepsilon(\theta) \\
& +\frac{\mu^{-1} \cdot\left(g^{\prime \prime}\left(m_{s}^{*}(\theta)\right)\right)^{-1} \cdot \mathbb{E}\left[\left(g^{\prime \prime}\left(m_{s}^{*}(\theta)\right)\right)^{-1} \varepsilon(\theta)\right]}{\left(g^{\prime \prime}\left(\bar{p}_{s}^{*}\right)\right)^{-1}-\mathbb{E}\left[\left(g^{\prime \prime}\left(m_{s}^{*}(\theta)\right)\right)^{-1}\right]} .
\end{aligned}
$$

Proof of Lamma 6. Taking derivative with respect to $\alpha$ at $\alpha=0$ for both sides of (3.6) leads to

$$
\begin{aligned}
\mu^{-1} \varepsilon(\theta)= & \left.g^{\prime \prime}\left(m_{s}^{*}(\theta)\right) \cdot \frac{\partial m_{s}(\theta)}{\partial \alpha}\right|_{\alpha=0} \\
& -\left.g^{\prime \prime}\left(\bar{p}_{s}^{*}\right) \cdot \mathbb{E} \frac{\partial m_{s}(\theta)}{\partial \alpha}\right|_{\alpha=0}
\end{aligned}
$$


Take expectation of both sides and we get

$$
\begin{aligned}
& \mathbb{E}\left[\left.\frac{\partial m_{s}(\theta)}{\partial \alpha}\right|_{\alpha=0}\right] \\
= & \mu^{-1} \cdot\left(1-\mathbb{E}\left[\left(g^{\prime \prime}\left(m_{s}^{*}(\theta)\right)\right)^{-1}\right] \cdot g^{\prime \prime}\left(\bar{p}_{s}^{*}\right)\right)^{-1} \cdot \mathbb{E}\left[\left(g^{\prime \prime}\left(m_{s}^{*}(\theta)\right)\right)^{-1} \varepsilon(\theta)\right] .
\end{aligned}
$$

Combining the above two equations leads to (A.10). This concludes the proof of Lemma 6.

We continue with the proof of Lemma 1. The first term of the right hand side of (A.10) is the investor's local response to $\varepsilon(\theta)$. It is of the same sign as the perturbation $\varepsilon(\theta)$. When the repayment of the security increases at state $\theta$, the investor is more likely to accept the security at this state. The second term measures the investor's average response to perturbation $\varepsilon(\theta)$ over all states. It is straightforward to verify that the denominator of the second term is positive due to Jensen's inequality. As a result, if the perturbation increases the investor's repayment on average over all states, she is more likely to accept the security as well.

Now we can calculate the variation of the entrepreneur's expected payoff $u_{E}(s(\theta))$, according to condition (3.7). Taking derivative of $u_{E}(s(\theta))$ with respect to $\alpha$ at $\alpha=0$ leads to

$$
\left.\frac{\partial u_{E}(s(\theta))}{\partial \alpha}\right|_{\alpha=0}=\mathbb{E}\left[\left.\frac{\partial m_{s}(\theta)}{\partial \alpha}\right|_{\alpha=0}(\theta-s(\theta))\right]-\mathbb{E}\left[m_{s}^{*}(\theta) \cdot \varepsilon(\theta)\right]
$$

Substitute (A.10) into (A.11) and we get

$$
\left.\frac{\partial u_{E}(s(\theta))}{\partial \alpha}\right|_{\alpha=0}=\mathbb{E}[r(\theta) \cdot \varepsilon(\theta)]
$$

where

$$
r(\theta)=-m_{s}^{*}(\theta)+\mu^{-1} \cdot\left(g^{\prime \prime}\left(m_{s}^{*}(\theta)\right)\right)^{-1} \cdot\left(\theta-s^{*}(\theta)+w^{*}\right)
$$

and

$$
w^{*}=\mathbb{E}\left[\left(\theta-s^{*}(\theta)\right) \frac{g^{\prime \prime}\left(\bar{p}_{s}^{*}\right)}{g^{\prime \prime}\left(m_{s}^{*}(\theta)\right)}\right]\left(1-\mathbb{E}\left[\frac{g^{\prime \prime}\left(\bar{p}_{s}^{*}\right)}{g^{\prime \prime}\left(m_{s}^{*}(\theta)\right)}\right]\right)^{-1} .
$$

Note that $w^{*}$ is a constant that does not depend on $\theta$ and will be endogenously determined in the equilibrium. Besides, $r(\theta)$ is the Frechet derivative of the entrepreneur's expected payoff $u_{E}(s(\theta))$ at $s^{*}(\theta)$, which measures the marginal contribution of any perturbation to the entrepreneur's expected payoff when the security is optimal. Specifically, the first term of (A.13) is the direct contribution of perturbing $s^{*}(\theta)$ disregarding the variation of $m_{s}^{*}(\theta)$, and the second term measures the indirect contribution through the variation of $m_{s}^{*}(\theta)$. This Frechet derivative $r(\theta)$ plays an important role in shaping the entrepreneur's optimal security.

To further characterize the optimal security, we discuss the Frechet derivative $r(\theta)$ in detail. Recall that the optimal security would be restricted by the feasibility condition $0 \leqslant s^{*}(\theta) \leqslant \theta$. Let

$$
A_{0}=\left\{\theta \in \Theta: \theta \neq 0, s^{*}(\theta)=0\right\},
$$




$$
A_{1}=\left\{\theta \in \Theta: \theta \neq 0,0<s^{*}(\theta)<\theta\right\}
$$

and

$$
A_{2}=\left\{\theta \in \Theta: \theta \neq 0, s^{*}(\theta)=\theta\right\}
$$

Clearly, $\left\{A_{0}, A_{1}, A_{2}\right\}$ is a partition of $\Theta \backslash\{0\}$. Since $s^{*}(\theta)$ is the optimal security, we have

$$
\left.\frac{\partial u_{E}(s(\theta))}{\partial \alpha}\right|_{\alpha=0} \leqslant 0
$$

for any feasible perturbation $\varepsilon(\theta) .{ }^{6}$ Hence, condition (A.12) implies

$$
r(\theta) \begin{cases}\leqslant 0 & \text { if } \theta \in A_{0} \\ =0 & \text { if } \theta \in A_{1} \\ \geqslant 0 & \text { if } \theta \in A_{2}\end{cases}
$$

According to Proposition 1, when the optimal security $s^{*}(\theta)$ induces the investor to acquire information, we have $0<m_{s}^{*}(\theta)<1$ for all $\theta \in \Theta$. Hence, condition (A.14) can be rearranged as

$$
\frac{r(\theta)}{m_{s}^{*}(\theta)}=-1+\mu^{-1} \cdot\left(1-m_{s}^{*}(\theta)\right) \cdot\left(\theta-s^{*}(\theta)+w^{*}\right)\left\{\begin{array}{l}
\leqslant 0 \text { if } \theta \in A_{0} \\
=0 \text { if } \theta \in A_{1} \\
\geqslant 0
\end{array} .\right.
$$

Recall condition (3.6), given the optimal security $s^{*}(\theta)$, the investor's optimal decision rule of information acquisition $m_{s}^{*}(\theta)$ is characterized by

$$
s^{*}(\theta)-k=\mu \cdot\left(g^{\prime}\left(m_{s}^{*}(\theta)\right)-g^{\prime}\left(\bar{p}_{s}^{*}\right)\right),
$$

where

$$
\bar{p}_{s}^{*}=\mathbb{E}\left[m_{s}^{*}(\theta)\right]
$$

is the investor's unconditional probability of accepting the optimal security $s^{*}(\theta)$. Conditions (A.15) and (A.16) as a system of functional equations jointly determine the optimal security $s^{*}(\theta)$ when it induces the investor's information acquisition.

Finally, when we focus on the unconstrained optimal security $\widehat{s}(\theta)$, note that is would not be restricted by the feasibility condition. Hence, the corresponding Frechet derivative $r(\theta)$ would be always zero at the optimum. On the other hand, the investor's optimal decision rule would not be affected. As a result, the conditions (A.16) and (A.15) become

$$
\widehat{s}(\theta)-k=\mu \cdot\left(g^{\prime}\left(\widehat{m}_{s}(\theta)\right)-g^{\prime}\left(\bar{p}_{s}^{*}\right)\right)
$$

where

$$
\bar{p}_{s}^{*}=\mathbb{E}\left[m_{s}^{*}(\theta)\right]
$$

\footnotetext{
${ }^{6} \mathrm{~A}$ perturbation $\varepsilon(\theta)$ is feasible with respect to $s^{*}(\theta)$ if there exists $\alpha>0$ such that for any $\theta \in \Theta, s^{*}(\theta)+\alpha \cdot \varepsilon(\theta) \in$ $[0, \theta]$.
} 
and

$$
\left(1-\widehat{m}_{s}(\theta)\right) \cdot\left(\theta-\widehat{s}(\theta)+w^{*}\right)=\mu
$$

where

$$
w^{*}=\mathbb{E}\left[\left(\theta-s^{*}(\theta)\right) \frac{g^{\prime \prime}\left(\bar{p}_{s}^{*}\right)}{g^{\prime \prime}\left(m_{s}^{*}(\theta)\right)}\right]\left(1-\mathbb{E}\left[\frac{g^{\prime \prime}\left(\bar{p}_{s}^{*}\right)}{g^{\prime \prime}\left(m_{s}^{*}(\theta)\right)}\right]\right)^{-1},
$$

in which $\bar{p}_{s}^{*}$ and $w^{*}$ are two constants that do not depend on $\theta$. This concludes the proof.

Proof of Lemma 2. From Lemma $1,\left(\widehat{s}(\theta), \widehat{m}_{s}(\theta)\right)$ satisfies the two differential equations (3.8) and (3.9). By condition (3.9), we get

$$
\widehat{m}_{s}(\theta)=1-\frac{\mu}{\theta-\widehat{s}(\theta)+w^{*}} .
$$

Substituting (A.17) into (3.8) leads to

$$
\mu^{-1}(\widehat{s}(\theta)-k)=g^{\prime}\left(\frac{\mu}{\theta-\widehat{s}(\theta)+w^{*}}\right)-g^{\prime}\left(\bar{p}_{s}^{*}\right) .
$$

Taking derivatives of both sides of the above equation with respect to $\theta$ leads to

$$
\begin{aligned}
\mu^{-1} \cdot \frac{\partial \widehat{s}(\theta)}{\partial \theta} & =g^{\prime \prime}\left(\widehat{m}_{s}(\theta)\right) \cdot \frac{\partial \widehat{m}_{s}(\theta)}{d \theta} \\
& =g^{\prime \prime}\left(\widehat{m}_{s}(\theta)\right) \cdot \frac{\mu \cdot\left(1-\frac{\partial \widehat{s}(\theta)}{\partial \theta}\right)}{\left(\theta-\widehat{s}(\theta)+w^{*}\right)^{2}} \\
& =\frac{1-\frac{\partial \widehat{s}(\theta)}{\partial \theta}}{\theta-\widehat{s}(\theta)+w^{*}-\mu}
\end{aligned}
$$

where we use

$$
g^{\prime \prime}(x)=\frac{1}{x(1-x)}
$$

while deriving the third equality. Manipulating the above equation we get

$$
\begin{aligned}
\frac{\partial \widehat{s}(\theta)}{\partial \theta} & =\frac{\mu}{\theta-\widehat{s}(\theta)+w^{*}} \\
& =1-\widehat{m}_{s}(\theta),
\end{aligned}
$$

where the last equality follows (A.17).

Again, taking derivatives of both sides of the above equation with respect to $\theta$ leads to

$$
\begin{aligned}
\mu^{-1} \cdot \frac{\partial \widehat{s}(\theta)}{\partial \theta} & =g^{\prime \prime}\left(\widehat{m}_{s}(\theta)\right) \cdot \frac{\partial \widehat{m}_{s}(\theta)}{\partial \theta} \\
& =\frac{1}{\widehat{m}_{s}(\theta)\left(1-\widehat{m}_{s}(\theta)\right)} \cdot \frac{\partial \widehat{m}_{s}(\theta)}{\partial \theta}
\end{aligned}
$$

Hence

$$
\begin{aligned}
\frac{\partial \widehat{m}_{s}(\theta)}{\partial \theta} & =\mu^{-1} \cdot \widehat{m}_{s}(\theta) \cdot\left(1-\widehat{m}_{s}(\theta)\right) \cdot \frac{\partial \widehat{s}(\theta)}{\partial \theta} \\
& =\mu^{-1} \cdot \widehat{m}_{s}(\theta) \cdot\left(1-\widehat{m}_{s}(\theta)\right)^{2}
\end{aligned}
$$

This completes the proof. 
Proof of Lemma 3. From Lemma 2, it is easy to see that the slope of $\widehat{s}(\theta)$ is always less than one. Hence, Lemma 3 is strightforward.

Proof of Lemma 4. We proceed by discussing three cases.

Case 1: We show that $\widehat{s}(\theta)>\theta$ would imply $s^{*}(\theta)=\theta$.

Suppose $s^{*}(\theta)<\theta$. Then we have $s^{*}(\theta)<\widehat{(\theta)}$. Since both $\left(s^{*}(\theta), m_{s}^{*}(\theta)\right)$ and $\left(\widehat{s}(\theta), \widehat{m}_{s}(\theta)\right)$ satisfy condition (3.6), we must have $m_{s}^{*}(\theta)<\widehat{m}_{s}(\theta)$. Therefore,

$$
\begin{aligned}
\frac{r(\theta)}{m_{s}^{*}(\theta)} & =-1+\mu^{-1} \cdot\left(1-m_{s}^{*}(\theta)\right) \cdot\left(\theta-s^{*}(\theta)+w^{*}\right) \\
& >-1+\mu^{-1} \cdot\left(1-\widehat{m}_{s}(\theta)\right) \cdot\left(\theta-\widehat{s}(\theta)+w^{*}\right) \\
& =0,
\end{aligned}
$$

which implies $s^{*}(\theta)=\theta$, a contradiction.

Note that, the logic for the inequality above is as follows. Since $\left(\widehat{s}(\theta), \widehat{m}_{s}(\theta)\right)$ satisfies condition (3.9), we must have $\theta-\widehat{\theta}+w^{*}>0$. Hence, $\widehat{s}(\theta)>s^{*}(\theta)$ implies that

$$
\theta-s^{*}(\theta)+w^{*}>\theta-\widehat{s}(\theta)+w^{*}>0 .
$$

Also note that $1-m_{s}^{*}(\theta)>1-\widehat{m}_{s}(\theta)>0$, we get the inequality above.

Hence, we have $s^{*}(\theta)=\theta$ in this case.

Case 2: We show that $\widehat{s}(\theta)<0$ would imply $s^{*}(\theta)=0$.

Suppose $s^{*}(\theta)>0$. Then we have $s^{*}(\theta)>\widehat{(}(\theta)$. By similar argument we know that $m_{s}^{*}(\theta)>$ $\widehat{m}_{s}(\theta)$. Therefore,

$$
\begin{aligned}
\frac{r(\theta)}{m_{s}^{*}(\theta)} & =-1+\mu^{-1} \cdot\left(1-m_{s}^{*}(\theta)\right) \cdot\left(\theta-s^{*}(\theta)+w^{*}\right) \\
& <-1+\mu^{-1} \cdot\left(1-\widehat{m}_{s}(\theta)\right) \cdot\left(\theta-\widehat{s}(\theta)+w^{*}\right) \\
& =0
\end{aligned}
$$

which implies $s^{*}(\theta)=0$. This is a contradiction. Hence, we have $s^{*}(\theta)=0$ in this case.

Case 3: We show that $0 \leqslant \widehat{s}(\theta) \leqslant \theta$ would imply $s^{*}(\theta)=\widehat{s}(\theta)$.

Suppose $\widehat{s}(\theta)<s^{*}(\theta)$. Then similar argument suggests $r(\theta) / m_{s}^{*}(\theta)<0$, which implies $s^{*}(\theta)=$ $0<\widehat{s}(\theta)$. This is a contradiction.

Similarly, suppose $s^{*}(\theta)<\widehat{s}(\theta)$. Similar argument suggests that $r(\theta) / m_{s}^{*}(\theta)>0$, which implies $s^{*}(\theta)=\theta>\widehat{s}(\theta)$. This is, again, a contradiction. Hence, we have $s^{*}(\theta)=\widehat{s}(\theta)$ in this case.

This concludes the proof.

Proof of Lemma 5. Apply Lemma 3 to Lemma 4, then Lemma 5 is strightforward. 
Proof of Proposition 4. We prove by contradiction. Suppose that the last two cases in Lemma 5 can occur in equilibrium. Hence, there exists a $\widetilde{\theta} \geqslant 0$, such that $s^{*}(\theta)=0$ when $0 \leqslant \theta \leqslant \widetilde{\theta}$ and $s^{*}(\theta)=\widehat{s}(\theta)$ when $\theta>\widetilde{\theta}$.

Note that, $s^{*}(\theta)$ is strictly increasing when $\theta>\widetilde{\theta}$. Also, since we focus on the equilibrium with information acquisition, there must exist a $\theta^{\prime \prime}$ such that $s^{*}\left(\theta^{\prime \prime}\right)>k$; otherwise the optimal security would be rejected without information acquisition. Therefore, there exists a $\theta^{\prime}>\widetilde{\theta}$ such that $s^{*}\left(\theta^{\prime}\right)=\widehat{s}\left(\theta^{\prime}\right)=k$. Recall condition (3.8), we have

$$
m_{s}^{*}\left(\theta^{\prime}\right)=\bar{p}_{s}^{*}
$$

Moreover, notice that we have $s^{*}\left(\theta^{\prime}\right) \in\left(0, \theta^{\prime}\right)$, we have

$$
\begin{aligned}
0=r\left(\theta^{\prime}\right) & =-m_{s}^{*}\left(\theta^{\prime}\right)+\mu^{-1} \cdot m_{s}^{*}\left(\theta^{\prime}\right) \cdot\left(1-m_{s}^{*}\left(\theta^{\prime}\right)\right) \cdot\left(\theta^{\prime}-s^{*}\left(\theta^{\prime}\right)+w^{*}\right) \\
& =-\bar{p}_{s}^{*}+\mu^{-1} \cdot \bar{p}_{s}^{*} \cdot\left(1-\bar{p}_{s}^{*}\right) \cdot\left(\theta^{\prime}-k+w^{*}\right) \\
& =\mu^{-1} \cdot \bar{p}_{s}^{*} \cdot\left(1-\bar{p}_{s}^{*}\right) \cdot\left(\theta^{\prime}-k\right)+\mathbb{E}[r(\theta)]
\end{aligned}
$$

where

$$
\begin{aligned}
\mathbb{E}[r(\theta)] & =-\bar{p}_{s}^{*}+\mu^{-1}\left(\mathbb{E}\left[\frac{\left.(\theta-s(\theta)) \cdot g^{\prime \prime}\left(\bar{p}_{s}^{*}\right)\right)}{g^{\prime \prime}(m(\theta))}\right] / g^{\prime \prime}\left(\bar{p}_{s}^{*}\right)+w^{*} \mathbb{E}\left[\frac{1}{g^{\prime \prime}(m(\theta))}\right]\right) \\
& =-\bar{p}_{s}^{*}+\mu^{-1}\left(w^{*} \cdot\left(1-\mathbb{E}\left[\frac{g^{\prime \prime}\left(\bar{p}_{s}^{*}\right)}{g^{\prime \prime}(m(\theta))}\right]\right) / g^{\prime \prime}\left(\bar{p}_{s}^{*}\right)+w^{*} \mathbb{E}\left[\frac{1}{g^{\prime \prime}(m(\theta))}\right]\right) \\
& =-\bar{p}_{s}^{*}+\frac{\mu^{-1} w^{*}}{g^{\prime \prime}\left(\bar{p}_{s}^{*}\right)} \\
& =-\bar{p}_{s}^{*}+\mu^{-1} \cdot \bar{p}_{s}^{*} \cdot\left(1-\bar{p}_{s}^{*}\right) \cdot w^{*} .
\end{aligned}
$$

We can express the expectation term $\mathbb{E}[r(\theta)]$ in another way. Note that, for any $\theta \in[0, \widetilde{\theta}]$, by definition we have

$$
\begin{aligned}
r(\theta) & =-m_{s}^{*}(\theta)+\mu^{-1} \cdot m_{s}^{*}(\theta) \cdot\left(1-m_{s}^{*}(\theta)\right) \cdot\left(\theta-s^{*}(\theta)+w^{*}\right) \\
& =-\widehat{m}_{s}(\widetilde{\theta})+\mu^{-1} \cdot \widehat{m}_{s}(\widetilde{\theta}) \cdot\left(1-\widehat{m}_{s}(\widetilde{\theta})\right) \cdot\left(\theta-0-\theta^{*}+\theta^{*}+w^{*}\right) \\
& =r(\widetilde{\theta})-\mu^{-1} \cdot \widehat{m}_{s}(\widetilde{\theta}) \cdot\left(1-\widehat{m}_{s}(\widetilde{\theta})\right) \cdot(\widetilde{\theta}-\theta) \\
& =-\mu^{-1} \cdot \widehat{m}_{s}(\widetilde{\theta}) \cdot\left(1-\widehat{m}_{s}(\widetilde{\theta})\right) \cdot(\widetilde{\theta}-\theta) .
\end{aligned}
$$

Also, as $s^{*}(\theta)=\widehat{s}(\theta)$ for any $\theta>\widetilde{\theta}$, we have $r(\theta)=0$ for all $\theta>\widetilde{\theta}$. Hence,

$$
\mathbb{E}[r(\theta)]=-\mu^{-1} \cdot \widehat{m}_{s}(\widetilde{\theta}) \cdot\left(1-\widehat{m}_{s}(\widetilde{\theta})\right) \int_{0}^{\widetilde{\theta}}(\widetilde{\theta}-\theta) d P(\theta) .
$$

Therefore, we have

$$
\begin{aligned}
\mu^{-1} \cdot \bar{p}_{s}^{*} \cdot\left(1-\bar{p}_{s}^{*}\right) \cdot\left(\theta^{\prime}-k\right) & =-\mathbb{E}[r(\theta)] \\
& =\mu^{-1} \cdot \widehat{m}_{s}(\widetilde{\theta}) \cdot\left(1-\widehat{m}_{s}(\widetilde{\theta})\right) \int_{0}^{\widetilde{\theta}}(\widetilde{\theta}-\theta) d P(\theta)
\end{aligned}
$$


Now we take the tangent line of $s^{*}(\theta)$ at $\theta=\widetilde{\theta}$. The tangent line intersects $s=k$ at $\widetilde{\theta}^{\prime}$, which is given by

$$
\frac{k}{\widetilde{\theta}^{\prime}-\theta^{\prime}}=\left.\frac{\partial s^{*}(\theta)}{\partial \theta}\right|_{\theta^{\prime}}=1-\widehat{m}_{s}(\widetilde{\theta})
$$

Hence, we have

$$
\widetilde{\theta}^{\prime}=\widetilde{\theta}+\frac{k}{1-\widehat{m}_{s}(\widetilde{\theta})}
$$

Also, note that we have shown that for any $\theta \geqslant \widetilde{\theta}$, we have

$$
\frac{\partial s^{*}(\theta)}{\partial \theta}=\frac{\partial \widehat{s}(\theta)}{\partial \theta}=1-\widehat{m}_{s}(\theta)=1-m_{s}^{*}(\theta) .
$$

Hence,

$$
\frac{\partial^{2} s^{*}(\theta)}{\partial \theta^{2}}=-\mu^{-1} \cdot m_{s}^{*}(\theta) \cdot\left(1-m_{s}^{*}(\theta)\right)^{2}<0 .
$$

Therefore, $s^{*}(\theta)$ is strictly concave for $\theta \geqslant \widetilde{\theta}$, and consequently, we also have $\widetilde{\theta^{\prime}}<\theta^{\prime}$.

As a result, from conditions (A.18) and (A.19), we have

$$
\begin{aligned}
\bar{p}_{s}^{*} \cdot\left(1-\bar{p}_{s}^{*}\right) \cdot\left(\widetilde{\theta}^{\prime}-k\right) & <\widehat{m}_{s}(\widetilde{\theta}) \cdot\left(1-\widehat{m}_{s}(\widetilde{\theta})\right) \int_{0}^{\widetilde{\theta}}(\widetilde{\theta}-\theta) d P(\theta) \\
& =\bar{p}_{s}^{*} \cdot\left(1-\bar{p}_{s}^{*}\right) \cdot\left(\widetilde{\theta}+\frac{\widehat{m}_{s}(\widetilde{\theta})}{1-\widehat{m}_{s}(\widetilde{\theta})} \cdot k\right) .
\end{aligned}
$$

By Jensen's inequality, we get

$$
\bar{p}_{s}^{*} \cdot\left(1-\bar{p}_{s}^{*}\right)>\mathbb{E}\left[m_{s}^{*}(\theta) \cdot\left(1-m^{*}(\theta)\right)\right] .
$$

Therefore, we have

$$
\begin{aligned}
\widehat{m}_{s}(\widetilde{\theta}) \cdot\left(1-\widehat{m}_{s}(\widetilde{\theta})\right) \int_{0}^{\widetilde{\theta}}(\widetilde{\theta}-\theta) d P(\theta) & >\bar{p}_{s}^{*} \cdot\left(1-\bar{p}_{s}^{*}\right) \cdot\left(\widetilde{\theta}+\frac{\widehat{m}_{s}(\widetilde{\theta})}{1-\widehat{m}_{s}(\widetilde{\theta})} \cdot k\right) \\
& >\mathbb{E}\left[m_{s}^{*}(\theta) \cdot\left(1-m^{*}(\theta)\right)\right] \cdot\left(\widetilde{\theta}+\frac{\widehat{m}_{s}(\widetilde{\theta})}{1-\widehat{m}_{s}(\widetilde{\theta})} \cdot k\right) .
\end{aligned}
$$

Expand the expectation term above and rearrange, we get

$$
\begin{aligned}
& \widehat{m}_{s}(\widetilde{\theta})^{2} \cdot k \cdot \operatorname{Pr}(\theta \leqslant \widetilde{\theta})+\int_{\widetilde{\theta}}^{+\infty} m_{s}^{*}(\theta) \cdot\left(1-m_{s}^{*}(\theta)\right) d P(\theta) \cdot\left(\widetilde{\theta}+\frac{\widehat{m}_{s}(\widetilde{\theta})}{1-\widehat{m}_{s}(\widetilde{\theta})} \cdot k\right) \\
< & \widehat{m}_{s}(\widetilde{\theta}) \cdot\left(1-\widehat{m}_{s}(\widetilde{\theta})\right) \int_{0}^{\tilde{\theta}}(-\theta) d P(\theta) \\
\leqslant & 0 .
\end{aligned}
$$

Nevertheless, the left hand side of the above inequality should be positive, which is a contradiction. This concludes the proof. 
Proof of Proposition 5. First, note that $s^{*}(\theta)$ is strictly increasing and continuous. Also, note that there exists a $\theta^{\prime \prime}$ such that $s^{*}\left(\theta^{\prime \prime}\right)>k$; otherwise, the offer will be rejected without information acquisition.

Therefore, there exists an unique $\theta^{\prime}$ such that $s^{*}\left(\theta^{\prime}\right)=k$, which ensures that $m_{s}^{*}\left(\theta^{\prime}\right)=\bar{p}_{s}^{*}$, and

$$
\begin{aligned}
r\left(\theta^{\prime}\right) & =-\bar{p}_{s}^{*}+\mu^{-1} \cdot \bar{p}_{s}^{*} \cdot\left(1-\bar{p}_{s}^{*}\right) \cdot\left(\theta^{\prime}-s^{*}\left(\theta^{\prime}\right)+w^{*}\right) \\
& =\mu^{-1} \cdot \bar{p}_{s}^{*} \cdot\left(1-\bar{p}_{s}^{*}\right) \cdot\left(\theta^{\prime}-s^{*}\left(\theta^{\prime}\right)\right)+\mathbb{E}\left[r\left(\theta^{\prime}\right)\right] .
\end{aligned}
$$

Note that $\mathbb{E}\left[r\left(\theta^{\prime}\right)\right]>0$ and $\theta^{\prime}-s^{*}\left(\theta^{\prime}\right) \geqslant 0$, we have thet $a^{\prime}<\widehat{(\theta)}$. As $\theta^{\prime}=s^{*}\left(\theta^{\prime}\right)=k$, it follows that $\widehat{\theta}>\theta^{\prime}=k$. This concludes the proof.

Proof of Proposition 6. When we have $\mathbb{E}[\theta] \leqslant k$ and $\mathbb{E}\left[\exp \left(\mu^{-1}(t \cdot \theta-k)\right)\right]>1$, according to Proposition 1, even if the entrepreneur proposes all the future cash flow to the investor, the security would induce the investor to acquire information and accept it with positive but less than one probability. This concludes the proof. 